\title{
Flexural and shear strengthening of reinforced concrete beams with a hybrid CFRP solution
}

\author{
S.J.E. Dias*, J.R.M. Silva, J.A.O. Barros \\ ISISE, Institute of Science and Innovation for Bio-Sustainability (IB-S), Department of Civil Engineering, University of Minho, Guimarães, Portugal
}

\section{A R T I C L E I N F O}

\section{Keywords:}

RC beams

Simultaneous flexural and shear strengthening NSM CFRP laminates

EBR CFRP wet lay-up strips of sheets

Experimental results

\begin{abstract}
A B S T R A C T
An experimental program was carried out for assessing the performance of a hybrid solution composed by CFRP systems for the simultaneous flexural and shear strengthening of RC beams. CFRP laminates, applied according to NSM technique, are used for the flexural strengthening, while U-shape CFRP discrete strips of wet lay-up sheet, applied according to the EBR technique, are adopted for the shear strengthening. An anchorage system was applied at the extremities of these CFRP strips in an attempt of avoiding their premature debonding. The experimental results showed the hybrid strengthening solution is very effective, not only in terms of increasing the load carrying capacity of the beams, but also in assuring higher mobilization of the tensile capacity of the CFRP. The performance of the hybrid CFRP configuration that included the anchorage system for the shear strengthening was significantly higher than the one assured by other shear strengthening solutions that were applied in similar RC beams and tested until failure using the same test system adopted in this experimental program. The predictive performance of the ACI formulations proposed for estimating the contribution of CFRP systems for the flexural and shear resistance of RC beams was appraised considering the obtained experimental results.
\end{abstract}

\section{Introduction}

Due to high strength-to-weight ratio (low-density and high tensile strength), high durability (non susceptible to corrosion), electromagnetic neutrality, high fatigue resistance, ease of handling, rapid execution with lower labor, and practically unlimited availability in size, geometry and dimension, carbon fiber reinforced polymer (CFRP) materials are being used as competitive alternatives on the structural strengthening of reinforced concrete (RC) structures [1].

For the flexural or for the shear strengthening of a RC beam, CFRP can be applied according to the followings two main techniques: Externally Bonded Reinforcement (EBR) where the CFRP (wet lay-up sheets or laminates) is bonded to the external tension face of the element to be strengthened, in the case of flexural strengthening [2,3], while for the shear strengthening, strips full wrapping the beam's cross section, disposed in a U-shape or applied in the lateral faces of the beam can be used [4-6]; Near Surface Mounted (NSM) where CFRP bars (circular, square or rectangular cross section) are introduced into pre-cut slits opened on the concrete cover of the elements to strengthen (tension face for flexural strengthening $[2,3,7,8]$, and lateral faces for shear strengthening [9-11]). Due to the largest bond area and higher con- finement provided by the surrounding concrete, narrow strips of CFRP laminates of rectangular cross section, installed into thin slits and bonded to concrete by an epoxy adhesive, are the most effective CFRP strengthening elements for the NSM technique [7]. Other advantage about the use of laminates is the simplicity of opening the slits where a single saw cut is normally enough for obtaining the slit, while round/ square bars require two saw cuts and the removal of the concrete in between [12].

Several experimental investigations have demonstrated, for the case of flexural strengthening $[2,3]$ or for the case of shear strengthening $[2,13]$ of RC beams, that NSM technique is more effective than the EBR technique with CFRP systems. This fact occurred because in NSM technique the ratio between the bonded area and the cross sectional area of the CFRP is larger than in the EBR, allowing a more efficient use of the reinforcement material (less prone to premature debonding and in some cases FRP failure can be achieved) with a higher ratio of CFRP strain at failure to its maximum strain.

While planning a strengthening intervention on a RC element, the increment of both flexural and shear load carrying capacity may be required. Furthermore, a RC element needs to be shear strengthened when its shear capacity falls below its flexural capacity after have been

\footnotetext{
* Corresponding author.

E-mail address: sdias@civil.uminho.pt (S.J.E. Dias).
} 
submitted to a flexural strengthening intervention (the shear failure mode of a RC element must be avoided since it is brittle and, therefore, unpredictable). In this context, the development of an effective CFRP strengthening solution that addresses both of these necessities is especially appealing.

When both the flexural and shear load carrying capacity must be increased, the exclusive use of an unique type of CFRP-based strengthening technique may not be the best solution. In fact, when the percentage of the CFRP flexural strengthening is relatively high, a premature debonding rupture failure mode has large probability of occurring if EBR technique is used due to the significant in-plane shear strain gradients developed between concrete substrate and CFRP systems in their extremities, in consequence of the relatively high axial stiffness of these systems [14]. In its turn, CFRP laminates applied on the lateral faces of the beam according to the NSM technique for increasing its shear capacity do not contribute for avoiding the occurrence of the aforementioned EBR premature debonding failure mode. Furthermore, when the shear reinforcement ratio requires small spacing between NSM CFRP laminates, a detachment of the concrete cover layer where these laminates are introduced can occur without a significant mobilization of the strengthening capacity of the laminates [15].

To address the concerns above mentioned, it was developed an hybrid solution using CFRP for the flexural and shear strengthening of RC beams. For the flexural strengthening it was adopted the NSM technique with CFRP laminates due the obtained excellent results compared to the EBR technique [2,3]. The NSM CFRP laminates for the flexural strengthening are, however, susceptible of failing due to the premature rip-off failure mode, also designated by End Concrete Cover Separation failure mode [16]. To simultaneous assure the required shear capacity and avoid this type of failure mode for the NSM CFRP laminates, the adopted CFRP shear strengthening solution is composed by discrete strips of EBR U-shape CFRP wet lay-up sheets that wrap the laminates. The extremities of these discrete strips are anchored to the compressive zone of the RC beam in order to delay their eventual sudden debonding.

To appraise the performance of the application of the above mentioned hybrid solution using CFRP for the flexural and shear strengthening of RC beams, an experimental program was carried out. This experimental program is described in detail (series of beam prototypes, materials properties, definition of the bond area for the connection of two layers of wet lay-up CFRP sheets, application of the CFRP, test set-up and monitoring system), the results of the tests are presented and discussed, and the relevant conclusions are pointed out. The results are presented and analyzed in terms of the structural behavior of the tested beams, modes of failure and effectiveness of the adopted hybrid solution using CFRP. Taking into account available experimental results obtained with the same test set-up and using similar RC beams shear strengthened with NSM CFRP laminates or shear strengthened with discrete strips of EBR U-shaped CFRP wet lay-up sheets, the performance of the adopted anchorage system was assessed. Furthermore, the predictive performance of the ACI formulations [17] proposed for the contribution of CFRP systems for flexural and for the shear resistance of RC beams was appraised by taking the results obtained in the present experimental program.

\section{Experimental program}

\subsection{Series of beam prototypes}

The experimental program is composed of two series of RC beams with $\mathrm{T}$ cross section (series I and series II) that differ in the amount of tensile steel reinforcements, in the number of steel stirrups and in the number of layers of the CFRP shear strengthening (Fig. 1 and Table 1). Each series contains three beams: the reference beam without CFRP (beam REF-I in series I and beam REF-II in series II); one beam equiv- alent to the reference beam, but flexural (with NSM CFRP laminates) and shear (with EBR strips of wet lay-up CFRP sheets of U configuration) strengthened with CFRP (beam SFS-I in series I and beam SFSII in series II); one beam equivalent to the SFS beam (beam SFS-I in series I and beam SFS-II in series II), but where the EBR strips have the anchorage system described in Section 2.2 (beam SFSA-I in series I and beam SFSA-II in series II).

The beams were $2800 \mathrm{~mm}$ long ( $2400 \mathrm{~mm}$ between the supports) with a $\mathrm{T}$ cross section of $450 \times 100 \mathrm{~mm}$ for the width $\times$ depth of the flange and $180 \times 300 \mathrm{~mm}$ for the width $\times$ depth of the web. The longitudinal steel reinforcement in the flange for all beams consisted of 6 bars of $12 \mathrm{~mm}$ diameter $(6 \phi 12)$. For the tensile steel reinforcements, 3 bars of $20 \mathrm{~mm}$ diameter ( $3 \phi 20$ ) were adopted in the beams of series I, while 2 bars of $20 \mathrm{~mm}$ diameter and 1 bar of $25 \mathrm{~mm}$ diameter $(2 \phi 20+1 \phi 25)$ were applied in the beams of series II. According to Fig. 1, steel stirrups of $6 \mathrm{~mm}$ diameter spaced at $300 \mathrm{~mm}(\phi 6 @ 300 \mathrm{~mm})$ and at $150 \mathrm{~mm}(\phi 6 @ 150 \mathrm{~mm})$ were adopted as transverse reinforcement in the specimens of series I and II, respectively.

The configurations of the CFRP for the flexural and shear strengthening of the SFS-I (series I) and SFS-II (series II) beams were designed in order these beams fail in shear and, consequently, to evaluate the performance of the proposed anchorage system for the CFRP shear strengthening adopted in beams SFSA-I (series I) and SFSA-II (series II).

To localize the shear failure in only one of the beam shear spans, a three point loading configuration with a distinct length for the beam shear spans was selected, as shown in Fig. 1. The beam span $a$ was 2.5 times the effective depth $(d)$ of the beams $(a / d=2.5)$, since according to the available research [18], this is approximately the minimum value that assures a negligible arch effect from the point load to the closest reaction support. To prevent brittle spalling of the concrete cover at the supports, the beam's ends were strengthened by confining the concrete with a two-directional cage of $\phi 6 @ 65 \mathrm{~mm}$ horizontal and $\phi 10 @ 50 \mathrm{~mm}$ vertical stirrups (see in Fig. 1 the identification of these reinforcements in the right part of the beams REF-I and REF-II).

For the flexural strengthening of the RC beams, four CFRP laminates of $1.4 \mathrm{~mm}$ (thickness) $\times 10 \mathrm{~mm}$ (depth) cross section dimensions were applied using the NSM technique (it was adopted the same distance between consecutive laminates, $36 \mathrm{~mm}$ ). The length of the laminates was $2300 \mathrm{~mm}$ and the distance between the extremities of the laminates and the supports was $50 \mathrm{~mm}$. In terms of shear strengthening, strips of two layers of EBR U-shape CFRP wet lay-up sheets of $60 \mathrm{~mm}$ width and $0.176 \mathrm{~mm}$ thickness were applied, with $150 \mathrm{~mm}$ of spacing, for strengthening the beams of series I, according to the scheme represented in Fig. 1. The same amount and distribution of strips of EBR U-shape CFRP wet lay-up sheets were adopted for strengthening the beams of series II, but adopting only one layer.

The details of the tested beams are indicated in Table 1. This table shows that the tested beams had a percentage of longitudinal tensile steel bars $\left(\rho_{s l}\right)$ ranging from $1.46 \%$ (series I) to $1.74 \%$ (series II), a percentage of steel stirrups $\left(\rho_{s w}\right)$ ranging from $0.1 \%$ (series I) to $0.21 \%$ (series II), a percentage of NSM CFRP laminates $\left(\rho_{f l}\right)$ of $0.08 \%$ and a percentage of wet lay-up CFRP sheets $\left(\rho_{f w}\right)$ ranging from $0.08 \%$ (series II) to $0.16 \%$ (series I).

\subsection{Material properties}

The compressive strength [19] and Young's modulus [20] of the concrete were evaluated at the age of the beam tests, by carrying out direct compression tests with cylinders of $150 \mathrm{~mm}$ diameter and $300 \mathrm{~mm}$ height. The values of the main tensile properties of the high bond steel bars (6, 20 and $25 \mathrm{~mm}$ diameter) used in the tested beams were obtained from uniaxial tensile tests performed according to the recommendations of EN 10002 [21]. CFK 150/2000 S\&P laminates (flexural strengthening) and S\&P $240\left(300 \mathrm{~g} / \mathrm{m}^{3}\right)$ sheets (shear 


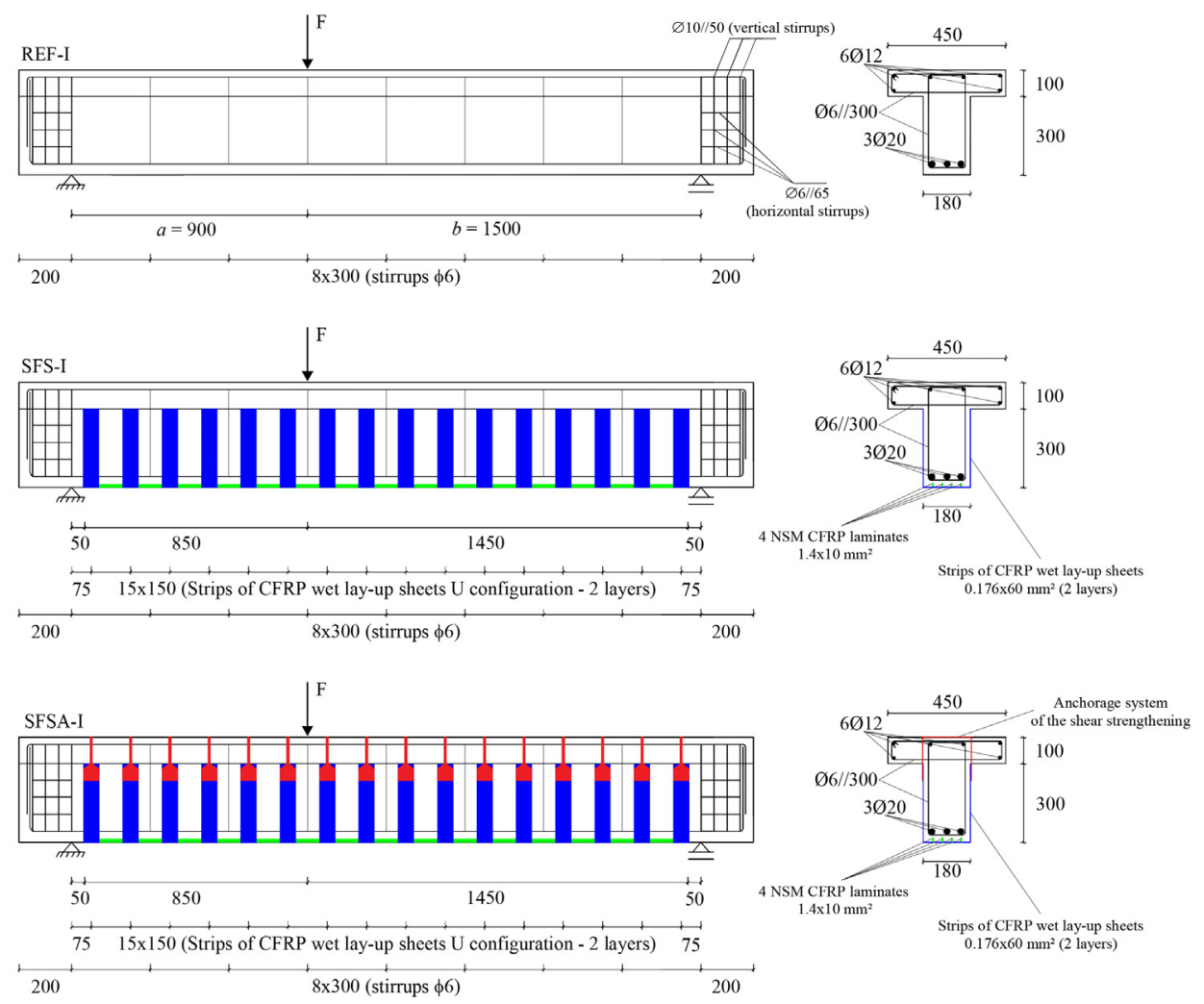

a)
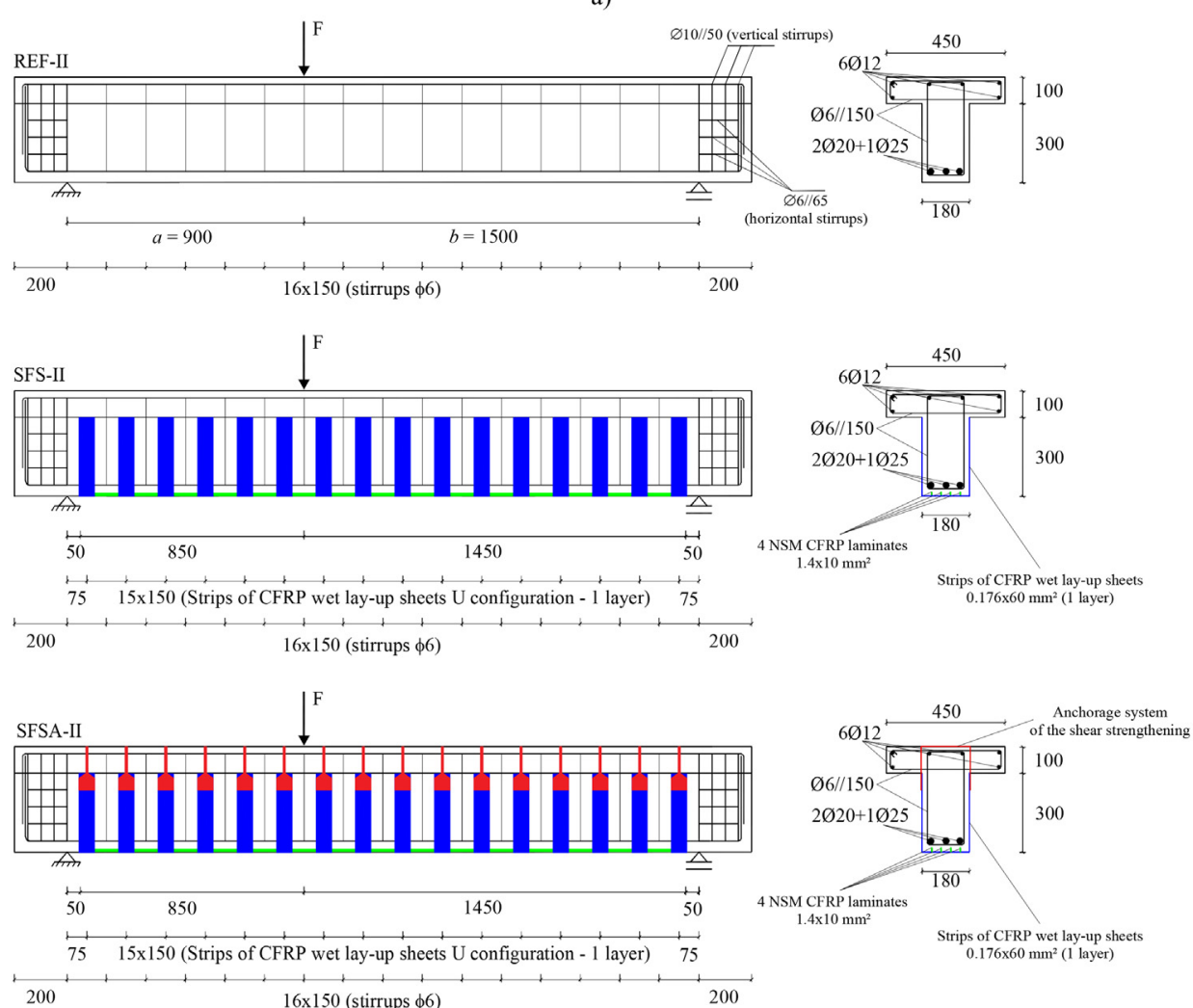

b)

Fig. 1. Series of the tested RC beams (dimensions in mm): a) series I (beams REF-I, SFS-I and SFSA-I); b) series II (beams REF-II, SFS-II and SFSA-II).

strengthening) were used in the present experimental research, and the tensile properties were characterized by performing uniaxial tensile tests according to ISO 527-5 [22]. Table 2 includes the average val- ues of the main properties of concrete, steel bars, CFRP laminate and CFRP sheet obtained from the above mentioned experimental programs. 
Table 1

General information about the series of the tested RC beams.

\begin{tabular}{|c|c|c|c|c|c|c|c|c|c|c|}
\hline \multirow[t]{2}{*}{ Series } & \multirow[t]{2}{*}{ Beam } & \multirow[t]{2}{*}{$\rho_{s l}[\%]^{(\mathrm{a})}$} & \multirow[t]{2}{*}{$\rho_{s w}[\%]^{(\mathrm{b})}$} & \multicolumn{2}{|c|}{ CFRP flexural strengthening } & \multicolumn{5}{|l|}{ CFRP shear strengthening } \\
\hline & & & & Material & $\rho_{f t}[\%]^{(\mathrm{c})}$ & Material & $s_{f}[\mathrm{~mm}]$ & $\theta_{f}\left[{ }^{\circ}\right]$ & $\rho_{f w}[\%]^{(\mathrm{d})}$ & Anchorage \\
\hline \multirow[t]{3}{*}{ I } & REF-I & 1.46 & 0.10 & - & - & - & - & - & - & - \\
\hline & SFS-I & & & NSM CFRP laminates & 0.08 & Strips of EBR CFRP wet lay-up sheets & 150 & 90 & 0.16 & No \\
\hline & SFSA-I & & & & & of $U$ configuration -2 layers & & & & Yes \\
\hline \multirow[t]{3}{*}{ II } & REF-II & 1.74 & 0.21 & - & - & - & - & - & - & - \\
\hline & SFS-II & & & NSM CFRP laminates & 0.08 & Strips of EBR CFRP wet lay-up sheets & 150 & 90 & 0.08 & No \\
\hline & SFSA-II & & & & & of $U$ configuration -1 layer & & & & Yes \\
\hline
\end{tabular}

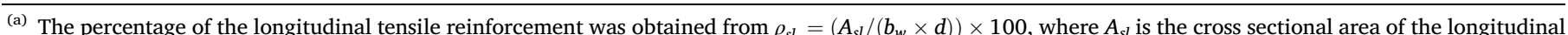

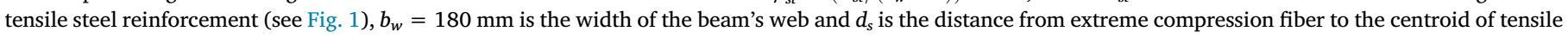
reinforcement.

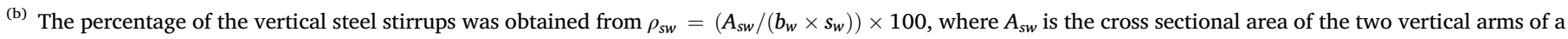
steel stirrup, and $s_{w}$ is the spacing of the stirrups.

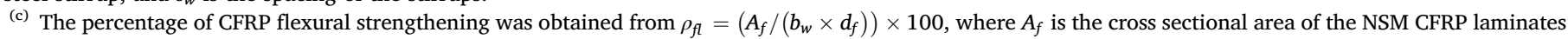
and $d_{f}$ is the distance from extreme compression fibre to the centroid of the NSM CFRP laminates.

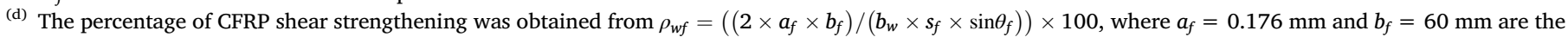

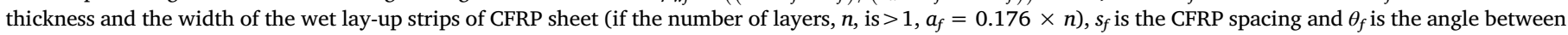
the CFRP fiber direction and the beam axis.

S\&P Resin 220 epoxy adhesive was used to bond the NSM CFRP laminates to the concrete substrate. The average values of the tensile strength, elasticity modulus and maximum strain of this adhesive, evaluated by Fernandes et al. [23] according to the ISO 527-2 recommendations [24], were about $30 \mathrm{MPa}, 7.2 \mathrm{GPa}$ and $3.6 \%$, respectively. S\&P Resin 55 epoxy adhesive was used for the application of the EBR wet lay-up CFRP sheets. According to the supplier, the average values of the tensile strength, elasticity modulus and maximum strain of this adhesive are about $35.8 \mathrm{MPa}, 2.6 \mathrm{GPa}$ and $23 \%$, respectively.

\subsection{Definition of the bond area for the connection of two layers of wet lay- up CFRP sheets}

In order to determine the overlap length between the U-shape CFRP strip and the adopted CFRP-based anchoring system for the CFRP shear strengthening configuration used in SFSA-I and SFSA-II beams, an experimental program of direct tensile tests with the three specimens shown in Fig. 2 was executed. Each specimens is formed by two strips of one layer of wet lay-up CFRP sheet $(170 \mathrm{~mm}$ in length and $50 \mathrm{~mm}$ in width) that were bonded to each other in such a way that the blanket overlap length was $40 \mathrm{~mm}$ (Fig. 2a), which corresponds to a bond area in the connection of the two strips equal to $50 \times 40=2000 \mathrm{~mm}^{2}$. The aim of these tests was to evaluate if the adopted bond area $\left(2000 \mathrm{~mm}^{2}\right)$ was enough to prevent the failure by debonding in the conection of the two strips of CFRP. To avoid premature rupture of the test specimens, due to the stress concentrations provided by the machine fixtures, two kinds of tabs were glued to the ends of each specimen (one layer of wet lay-up CFRP sheet with

Table 2

Average values of the properties of intervening materials.

\begin{tabular}{llll}
\hline Concrete & \multicolumn{2}{l}{$\begin{array}{l}\text { Compressive strength, } f_{c m} \text { (age of } \\
\text { slab tests) }\end{array}$} & $\begin{array}{l}\text { Elasticity modulus, } E_{c m} \text { (age } \\
\text { of slab tests) }\end{array}$ \\
\cline { 2 - 3 } & $f_{c m}=44.3 \mathrm{MPa}$ & $E_{c m}=34.1 \mathrm{GPa}$ \\
\hline Steel & Diameter & Yield stress, $f_{\text {sym }}$ & Tensile strength, $f_{\text {sum }}$ \\
& $\phi 6$ & $641 \mathrm{MPa}$ & $737 \mathrm{MPa}$ \\
& $\phi 20$ & $636 \mathrm{MPa}$ & $767 \mathrm{MPa}$ \\
CFRP Laminate & Tensile & $657 \mathrm{MPa}$ & $790 \mathrm{MPa}$ \\
& strength, $f_{\text {fum }}$ & modulus, $E_{f m}$ & Maximum strain, $\varepsilon_{f u}$ \\
& $3165 \mathrm{MPa}$ & $175 \mathrm{GPa}$ & $18.0 \%$ \\
CFRP wet lay- & Tensile & Elasticity & Maximum strain, $\varepsilon_{f u}$ \\
up sheet & strength, $f_{\text {fum }}$ & modulus, $E_{f m}$ & \\
& $3096 \mathrm{MPa}$ & $245 \mathrm{GPa}$ & $12.6 \%$ \\
\hline
\end{tabular}

$80 \mathrm{~mm}$ long and $50 \mathrm{~mm}$ wide was added to each side, complemented by the addition of a $50 \times 60 \mathrm{~mm}^{2}$ steel plate).

The tests were carried out using a servo-controlled testing machine with a load cell of $200 \mathrm{kN}$ capacity. The uniaxial tensile tests were executed under displacement control at a rate of $0.016 \mathrm{~mm} / \mathrm{s}$. The test setup and the appearance of the specimens after have been tested are shown in Fig. 2c and d, respectively.

As shown in Fig. 2d, it was found that a bond area of $2000 \mathrm{~mm}^{2}$ was sufficient to assure the full tensile capacity of the one CFRP layer, since all the tested specimens failed in this region (after testing it was verified that the bond area of the two CFRP strips was perfectly intact).

\subsection{Application of the CFRP strengthening}

To apply the flexural strengthening with NSM CFRP laminates, the following procedures were executed: i) a diamond cutter was used to open on the concrete cover of the tension face (of about $25 \mathrm{~mm}$ thickness) slits of $5 \mathrm{~mm}$ wide and $15 \mathrm{~mm}$ deep in accordance with the predefined arrangement for the laminates (the adopted spacing between the NSM CFRP laminates was $36 \mathrm{~mm}$ ); ii) the slits were cleaned by compressed air and the laminates (supplied in rolls of $150 \mathrm{~m}$, with a cross-section of $1.4 \times 10 \mathrm{~mm}^{2}$ ) were cut with a length of $2300 \mathrm{~mm}$ and then cleaned with acetone; iii) the epoxy adhesive was produced according to the supplier recommendations and then the slits were filled with the adhesive; iv) an adhesive layer was applied on the faces of the laminates and the laminates were inserted into the slits (Fig. 3a) and the adhesive in excess was removed.

To apply the wet lay-up CFRP strengthening system using the EBR technique, the following procedures were done. First, on the zones of the beam's surfaces where the strips of CFRP sheet were planned to be glued, an emery was applied to remove the superficial cement paste and to round out the beam's edges (with a radius of about $11 \mathrm{~mm}$ ) to reduce stress concentration in the CFRP, in these zones. In the case of the beams SFSA-I and SFSA-II (beams with the anchorage system for the CFRP shear strengthening), holes of $10 \mathrm{~mm}$ diameter were drilled along the depth of flange (the direction of the holes were approximately vertical), in the points corresponding to the midle of the width of each strip of U-shape CFRP strips (Fig. 3b). Then the zones of flange top surface where the strips of CFRP sheet were planned to be glued, an emery was applied to remove the superficial cement paste and to round out the zone around the holes. The residues were removed by compressed air. The unidirectional CFRP sheets were measured and cut in the desired shape and dimensions, and the S\&P Resin 55 epoxy adhesive was produced according to the supplier recommendations. In 


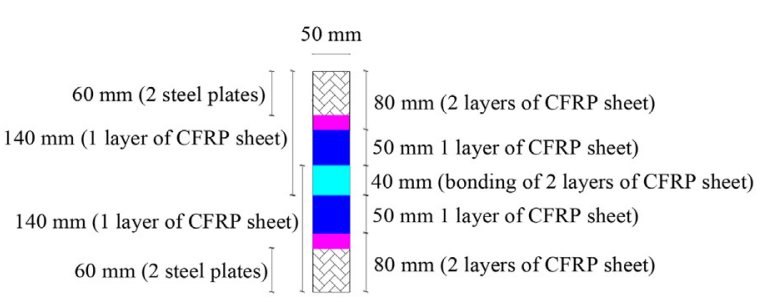

a)
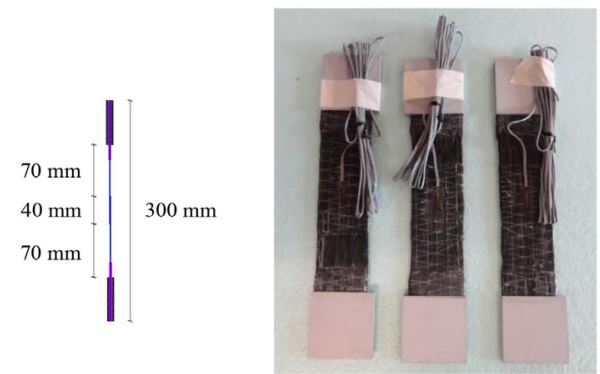

b)

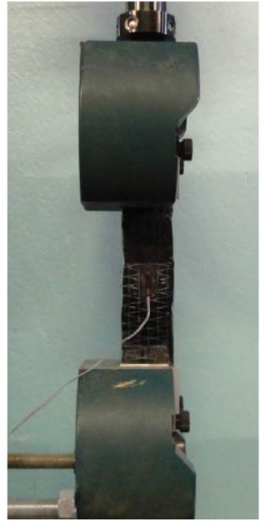

c)

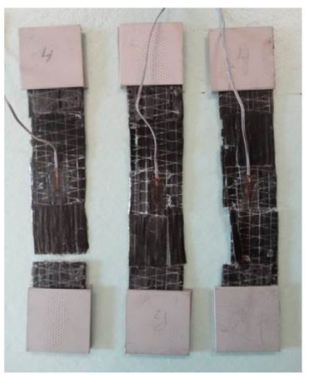

d)

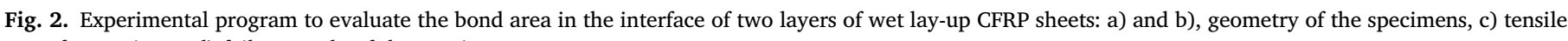
test of a specimen, d) failure mode of the specimens.

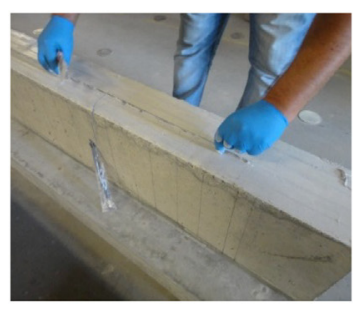

a)

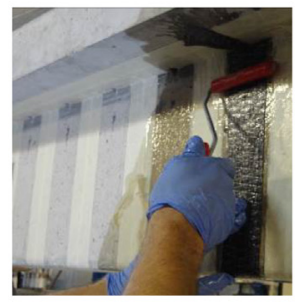

e)

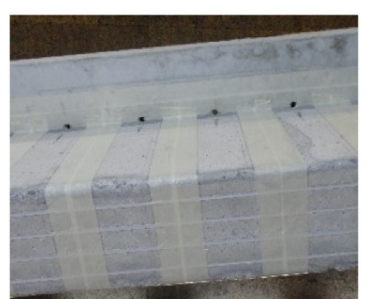

b)

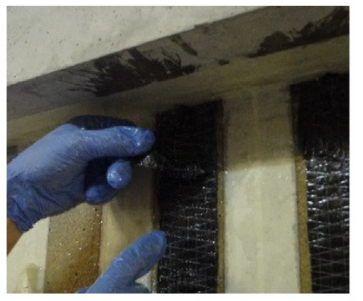

f)

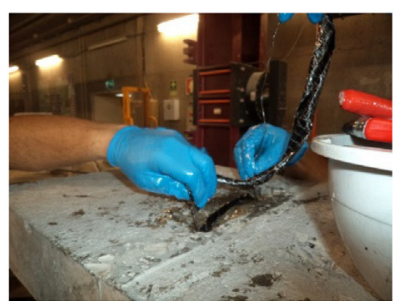

c)

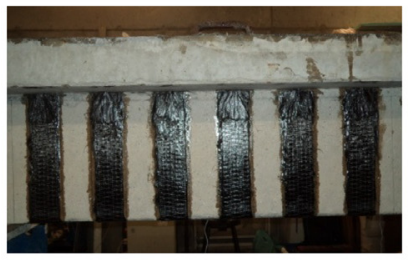

g)

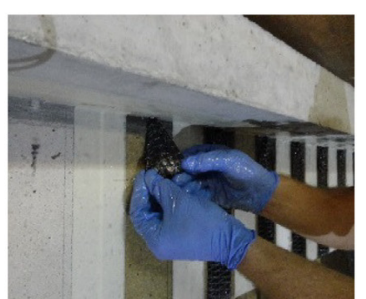

d)

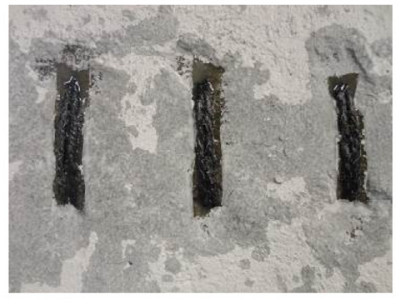

h)

Fig. 3. Flexural and shear strengthening of RC beam with a hybrid CFRP solution.

accordance with the pre-defined arrangement, the U-shaped CFRP strips were glued to the bottom and to the lateral faces of the beam, by using the epoxy resin (Fig. 3e). In the case of the beams SFSA-I and SFSA-II (those with the anchorage system for the CFRP shear strengthening), the strip of CFRP, which were previously rolled, were slowly introduced into the two holes from the top surface of the flange (Fig. $3 c$ and d), by getting a final inverted $U$ configuration. In each face of the web beam it was executed the conection between the U-shape CFRP strip (corresponding to the shear strengthening) and the inverted U CFRP strip corresponding to the anchorage system (with a minimum bonding surface of $2000 \mathrm{~mm}^{2}$ ) - see Fig. 3f. After the application of the first layer for the beams SFS-I and SFSA-I, it was executed the second layer (U-shaped CFRP for both beams and the inverted U CFRP strip for beam SFSA-I). The final aspect of the lateral and top surfaces of the flange of the beam SFSA-II is showed in Fig. $3 \mathrm{~g}$ and h, respectively (in Fig. $4 \mathrm{~b}$ it is possible to see a detail of the bottom surface of the beam SFSA-II).

To guarantee a proper curing of the adhesive (NSM CFRP laminates) and resin (EBR CFRP wet lay-up sheets), at least one week passed between the beam strengthening operations and the beam test. 


\subsection{Test setup and monitoring system}

Three point beam bending tests (Figs. 1 and 4a) were carried out using a servo closed-loop control equipment, taking the signal read in the displacement transducer (LVDT), placed at the loaded section to control the test at a displacement-control mode with a rate of $0.01 \mathrm{~mm} / \mathrm{second}$. The beams were instrumented (Fig. 4b) to measure the applied load, deflections and strains in the CFRP and in the tensile steel reinforcements. The deflection of the beams was measured by five displacement transducers (LVDT_1 to LVDT_5) as shown in Fig. 5a. To evaluate the strains on the steel bars, in all the tested beams, one strain gauge was installed in one of the bottom longitudinal steel bars (SG_SL) and in one of the steel stirrups (SG_SV) according to the configurations represented in Fig. $5 \mathrm{~b}$ (beams of the series I) and Fig. $5 \mathrm{c}$ (beams of the series II). In the strengthened beams, two strain gauges were installed in the NSM laminates (flexural strengthening): the SG_CL1 and SG_CL2 placed at the loaded section and at the middle of the $a$ shear span (Fig. $5 \mathrm{~b}$ and c). With the purpose of obtaining the strain variation along two strips of CFRP wet lay-up sheet that have the highest probability of providing the largest contribution for the shear strengthening of the RC beam, two strain gauges were bonded in each strip (SG_CV1, SG_CV2, SG_CV3, SG_CV4) as shown in Fig. 5b (beams of the series I) and Fig. 5c (beams of the series II). Cracking formation and propagation was continuously monitored during the test.

\section{Experimental results and discussion}

\subsection{Load carrying capacity of the tested beams}

The relationship between the applied force and the deflection at the loaded section, $F-u$, of the tested beams of series I is illustrated in Fig. 6a, where is possible to see that the CFRP strengthening configurations have improved the structural behavior of the beams in terms of stiffness and ultimate load carring capacity. In fact, for deflections higher than the one corresponding to the formation of the first shear crack in the reference beam ( $2.9 \mathrm{~mm}$ for a load of $155 \mathrm{kN}$ ), it is clear that the adopted CFRP shear strengthening configuration provided an increase in the beam's load carrying capacity. This reveals that the CFRP sheets (shear strengthening) bridging the surfaces of the shear crack offer resistance, mainly to crack opening, resulting to a smaller degradation of the shear stress transfer between the faces of the crack, due to aggregate interlock effect. Therefore, for deflections above the one corresponding to the formation of the shear crack in the reference beam (REF-I), an increase of the beam's stiffness was observed in the CFRP shear strengthened beams (SFS-I and SFS-II beams). This difference in the behavior of the reference beam and the CFRP strengthened beams was also occurred in the beams of the series II (Fig. 6b).

According to Fig. 6a, among the three tested beams of the series I, only beam SFSA-I has presented a ductile behavior. In fact, in beam SFSA-I the ratio between deflection at loaded section for $F_{\max }\left(u_{F \max }\right)$ and deflection at loaded-section for yield initiation $\left(u_{F s y}\right)$ was 2.8 . Similar scenario also occurred in the beams of series II, since only the beam SFSA-II reached a ductile behavior with a ratio between $u_{F \max }$ and $u_{F s y}$ of 3.2. In these two beams, SFSA-I and SFSA-II, the yielding load was respectively, $380 \mathrm{kN}$ and $430 \mathrm{kN}$, while the maximum load was $479 \mathrm{kN}$ and $526.2 \mathrm{kN}$. Between these two loading stages, these beams developed an almost linear force-deflection response, since in this stage the increment of load is mainly guaranteed by the contribution of the CFRP laminates that have linear elastic behavior. The stiffness in this phase of the beams SFSA-I and SFSA-II is the same because these beams had the same percentage of CFRP flexural strengthening $\left(\rho_{f l}\right)$. Beams SFS-I (Fig. 6a) and SFS-II (Fig. 6b) did not present a ductile behavior due the premature failure of these beams by shear (see Section 3.2).

Assuming that $\Delta F_{\max }=F_{\max }^{S t r}-F_{\max }^{R e f}$, being $F_{\max }^{R e f}$ and $F_{\max }^{S t r}$ the maximum force of the reference beam and of the CFRP strengthened beam, respectively, the $\Delta F_{\max } / F_{\max }^{R e f}$ ratio was evaluated. Assuming that $\Delta u_{F_{\max }}=u_{F_{\max }}^{S t r}-u_{F_{\max }}^{R e f}$, being $u_{F_{\max }}^{R e f}$ and $u_{F_{\max }}^{S t r}$ the deflection corresponding to the maximum force of the reference beam and of the CFRP strengthened beam, respectively, the $\Delta u_{F_{\max }} / u_{F_{\max }}^{R e f}$ ratio was also evaluated. The values for $F_{\max }, \Delta F_{\max } / F_{\max }^{R e f}, u_{F_{\max }}$ and $\Delta u_{F_{\max }} / u_{F_{\max }}^{R e f}$ are presented in Table 3. The failure mode of the beams (flexural or shear) is also presented in Table 3 - more details about the failure modes are provided in Section 3.2.

According to the results in Table 3, the values of the parameter $\Delta F_{\max } / F_{\max }^{R e f}$ of the tested CFRP strengthened beams have varied between $17.7 \%$ and $54.4 \%$. Regardless the series of the tested beams, the hybrid CFRP strengthening solution with the extremities of the Ushape CFRP strips anchored (beams SFSA-I and SFSA-II) had the high

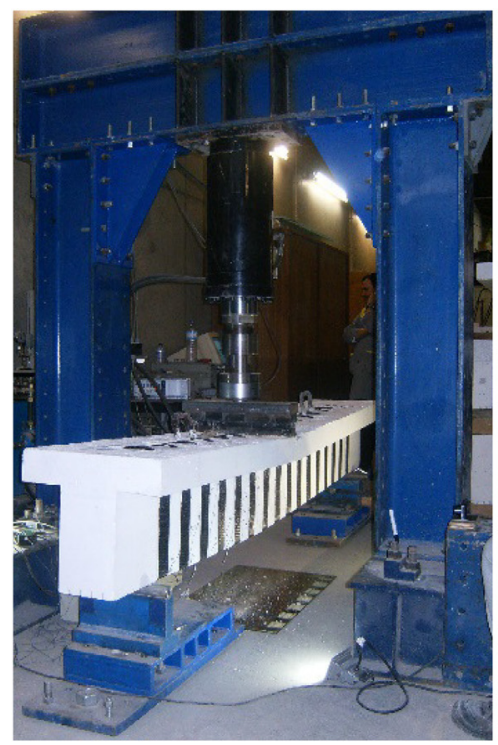

a)

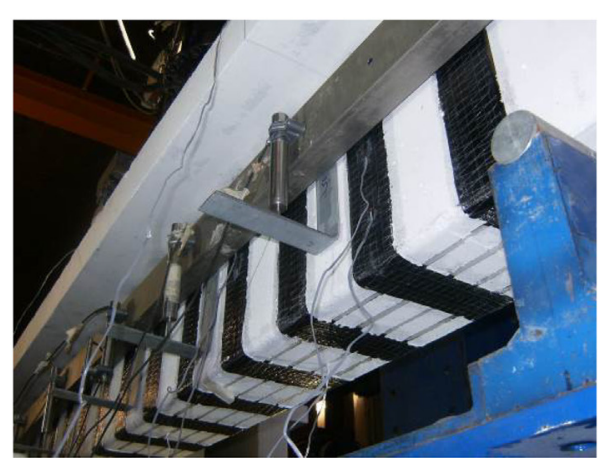

b)

Fig. 4. Test setup and monitoring system of the beams. 


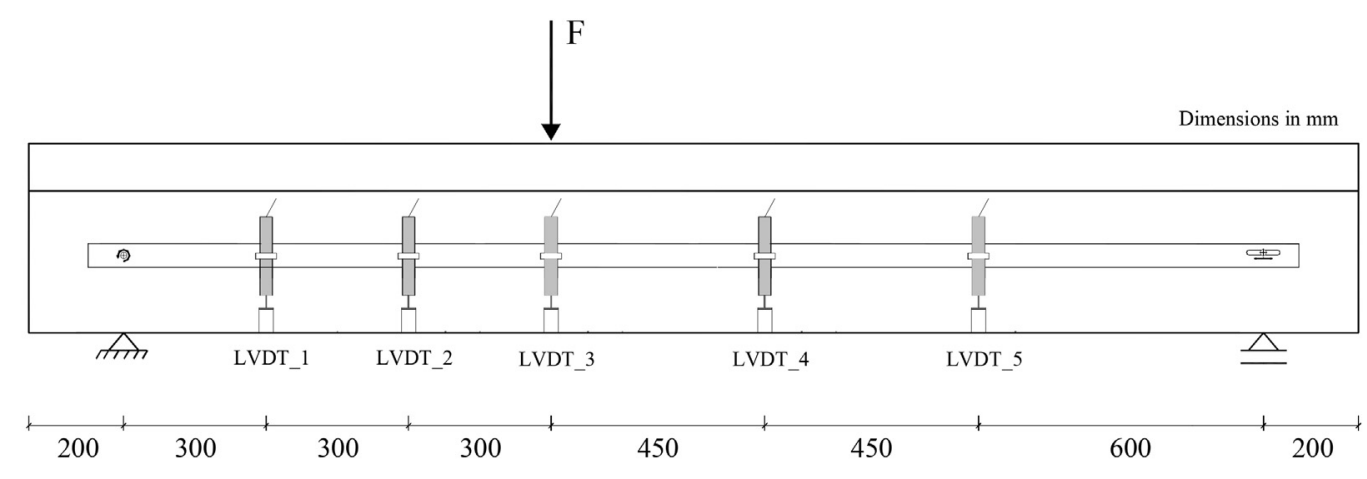

a)
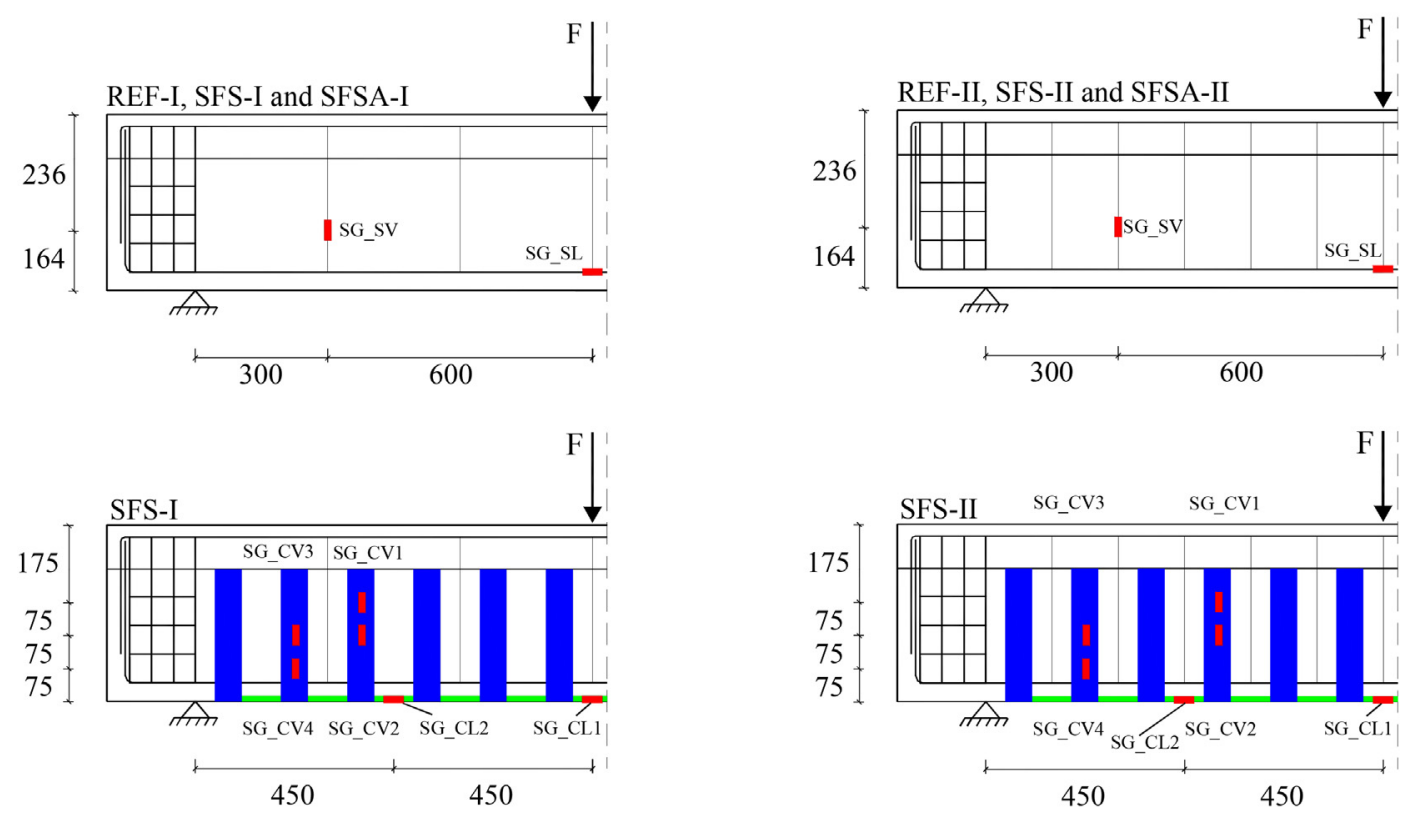

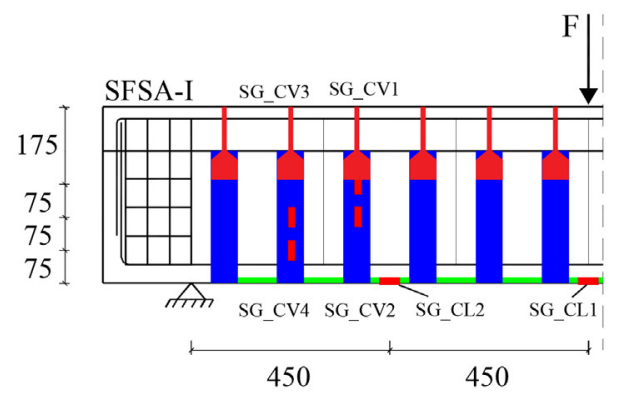

b)

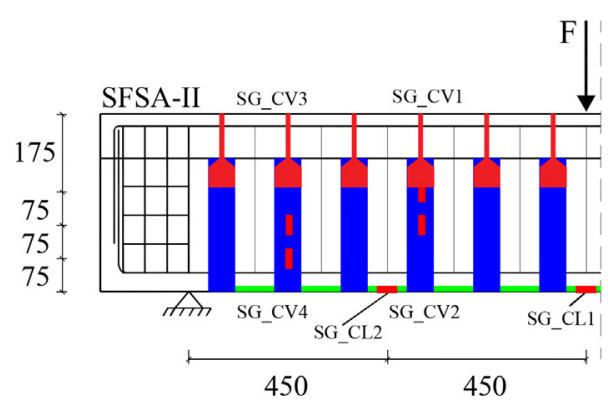

c)

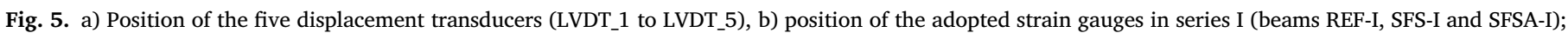
c) position of the adopted strain gauges in series II (beams REF-II, SFS-II and SFSA-II).

values of the increase in terms of beam's load carrying capacity $\left(\Delta F_{\max } / F_{\max }^{R e f}\right): 54.4 \%$ and $50.6 \%$ for the beams SFSA-I (Series I) and SFSA-II (Series II), respectively. For the strengthened beams without the anchorage system at the extremities of the U-shape CFRP strips, the value of $\Delta F_{\max } / F_{\max }^{R e f}$ was $17.9 \%$ (beam SFS-I of Series I) and $17.7 \%$ (beam SFS-II of Series II).

The deflection at the loaded section in correspondence to $F_{\max }$ $\left(u_{F_{\max }}\right)$ in the beams SFS-I and SFS-II was smaller than the value of $u_{F_{\max }}$ obtained in the corresponding reference beam (the value of $\Delta u_{F_{\max }}=u_{F_{\max }}^{S t r}-u_{F_{\max }}^{R e f}$ for the beams SFS-I and SFS-II was $-16.5 \%$ and $-38.1 \%$, respectively). In contrast, for the strengthened beams with the anchorage system at the extremities of the U-shape CFRP strips, the deflection at the loaded section in correspondence to $F_{\max }\left(u_{F_{\max }}\right)$ in the beams SFS-I and SFS-II was larger than the value of $u_{F_{\max }}$ obtained in the corresponding reference beam (the value of $\Delta u_{F_{\max }}=u_{F_{\max }}^{S t r}-u_{F_{\max }}^{R e f}$ for the beams SFS-I and SFS-II was $128.7 \%$ and $123.2 \%$, respectively).

The best performance of the beams with the anchorage system at the extremities of the U-shape CFRP strips is justified by the failure mode of the beams (Table 3). In fact, due the presence of the above mentioned anchorage system it was possible to change the failure mode of the beams (from a premature failure by shear in beams SFS- 


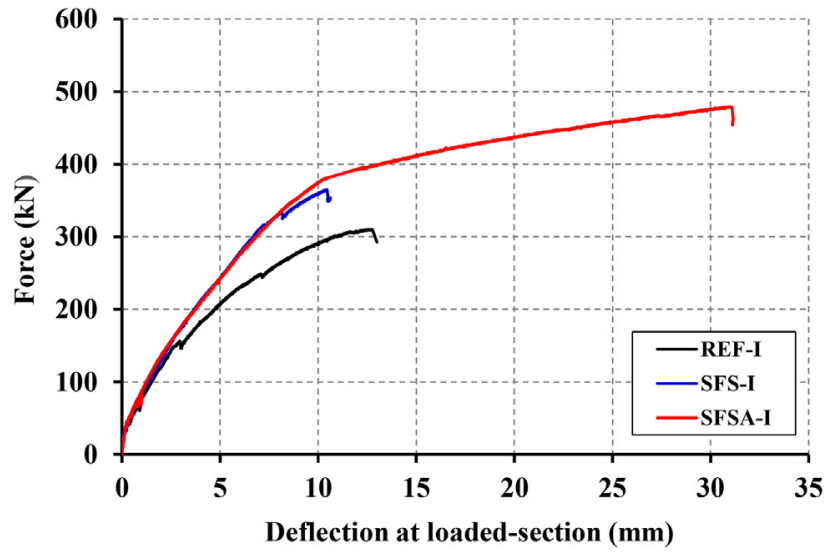

a) Series I

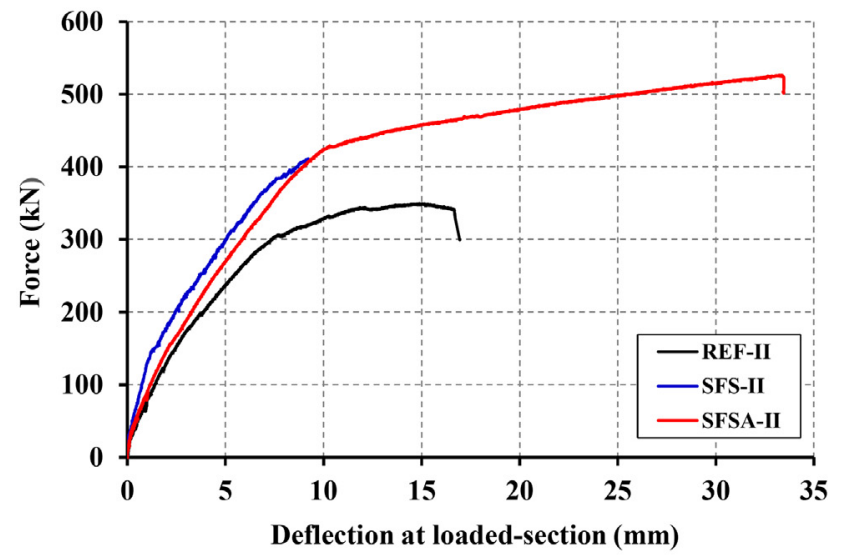

b) Series II

Fig. 6. Force vs. deflection at loaded section of the tested beams of: a) series I, b) series II.

I and SFS-II to a ductility failure mode by flexural in beams SFSA-I and SFSA-II).

\subsection{Crack pattern and failure modes}

Figs. 7 and 8 show the final crack pattern of the tested RC beams of series I and II, respectively. In all of the tested beams, the first cracks occurred (flexural cracks) near the load section. With the increase of the load, these cracks became wider and new cracks started to appear along the shear spans of the beams: first flexural-shear cracks and, in the case the beams failed in shear, one or two of these cracks have degenerated in shear failure cracks, while in the other beams, the failure cracks were of flexural nature (almost vertical).

As expected, the tested reference beams (REF-I and REF-II) failed in shear, with the shear failure crack localized in the shear span $a$ at the maximum load of $310.3 \mathrm{kN}$ (REF-I) and $349.5 \mathrm{kN}$ (REF-II). In these two beams the load was increased up to the moment when one stirrup that was crossing the shear failure crack has ruptured.

In the beams SFS-I and SFS-II, the failure mode, regardless the percentage of the CFRP shear strengthening, occurred by debonding of the wet lay-up CFRP sheets crossed by the shear failure crack (see Figs. 7 and 8). In the SFS-I beam, at a load level of about $330 \mathrm{kN}$, the strip of sheet 4 (Fig. 7) debonded at its top part. This was followed by a decay of the load carrying capacity of this beam (Fig. 6a). The load was transferred, mainly, to strip of sheet 5 (Fig. 7) and to the stirrup nearest the support, and the load was again increased up to the moment $\left(F_{\max }=365.1 \mathrm{kN}\right)$ when occurred the debonding of the strip of sheet 5 (Fig. 7), followed by a sudden and abrupt load decay. In case of SFS-II beam, at a load of $382 \mathrm{kN}$ the strip of sheet 4 (Fig. 8) debonded at its top part. Then, the load was increased up to the moment $\left(F_{\max }=411.4 \mathrm{kN}\right)$ when occurred the debonding of the strip of sheet 5 (Fig. 8), followed by a sudden and abrupt load decay.

The crack pattern of the beams of the series I at a load level of about $310 \mathrm{kN}$ (maximum load of the reference beam REF-I) is shown in Fig. 7. The effect of the CFRP shear strengthening in the control of the development of the critical shear crack is notable. The same effect is possible to see in Fig. 8 in terms of crack pattern of the beams of series II at a load level equal to the maximum load of the reference beam REF-II that was $350 \mathrm{kN}$. Figs. 7 and 8 evidence that the CFRP strengthening solutions have promoted the formation of a higher number of cracks and of smaller crack width when compared to the reference beam, which is responsible for the better performance of the strengthened beams.

Due the anchorage system implemented in the beams SFSA-I and SFSA-II, they did not fail in shear. In these beams, by avoiding the premature debonding of the U-shape CFRP strips, the shear stress transfer mechanisms in the shear cracks were more efficiently mobilized. Failure mode in these beams was by the rupture of the flexural strengthening (NSM CFRP laminates). Figs. 7 and 8 evidence that higher number of cracks have occurred in the beams with the anchorage system in the $\mathrm{U}$ strips of CFRP, with a clear localization of the flexural failure cracks.

\subsection{Strains in the CFRP laminates (flexural strengthening) and sheets (shear strengthening) and steel reinforcements}

Figs. 9 and 10 show, respectively for the beams of series I and II, the relationship between the applied load and the strains in the SG's positioned in the monitored longitudinal steel bars (SG_SL), steel stirrups (SG_SV), laminates (SG_CL) and sheets (SG_CV). Some of the adopted SG (Fig. 5) did not function properly and some others have interrupted their functioning before the beam's maximum load.

As shown in Figs. 9 and 10, the CFRP laminate (flexural strengthening) presented a linear strain evolution during the loading process with very small increase with the load up to the concrete crack initiation. Just after the concrete crack initiation a significant increase of strain was recording, and during the crack propagation stage up to the yield initiation of the flexural reinforcement, the load-strain rate $\left(F-\varepsilon_{C F R P}\right)$ in these SG was almost constant. In the beams failing in bending (those with anchorage mechanism for the U-shape strips), just after the yield initiation of the flexural steel reinforcement, another abrupt increase

Table 3

Experimental results of the tested RC beams.

\begin{tabular}{|c|c|c|c|c|c|c|}
\hline Series & Beam & $F_{\max }(\mathrm{kN})$ & $\Delta F_{\max } / F_{\max }^{R e f}(\%)$ & $u_{F \max }(\mathrm{mm})$ & $\Delta u_{F_{\max }} / u_{F_{\max }}^{R e f}(\%)$ & Failure mode \\
\hline \multirow[t]{3}{*}{ I } & REF-I & 310.3 & - & 12.54 & - & Shear \\
\hline & SFS-I & 365.1 & 17.9 & 10.44 & -16.5 & Shear \\
\hline & SFSA-I & 479.0 & 54.4 & 28.59 & 128.7 & Flexural \\
\hline \multirow[t]{3}{*}{ II } & REF-II & 349.5 & - & 14.89 & - & Shear \\
\hline & SFS-II & 411.4 & 17.7 & 9.22 & -38.1 & Shear \\
\hline & SFSA-II & 526.2 & 50.6 & 33.23 & 123.2 & Flexural \\
\hline
\end{tabular}



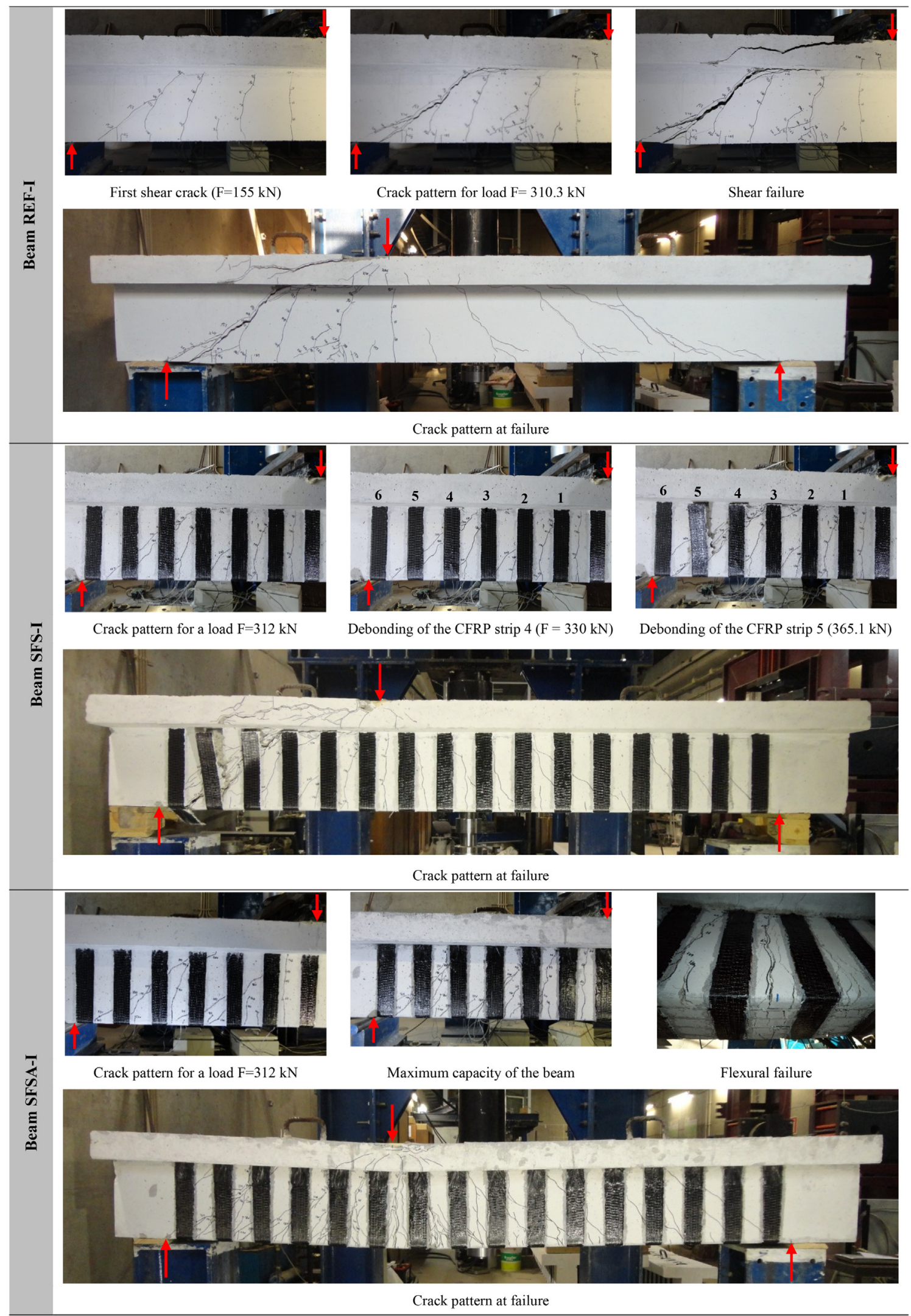

Fig. 7. Crack patterns and failure modes of the tested beams of series I.

of load-strain rate in the SG_CL was observed, which was caused by the incapacity of steel bars to support any significant extra load applied to the beam, and this rate was maintained almost constant up to the failure of these beams. The curves $F-\varepsilon_{C F R P}$ of the sheets (shear strengthening) featured two phases (this behavior was similar in the monitored stirrups). In the initial stage of loading, while the CFRP 

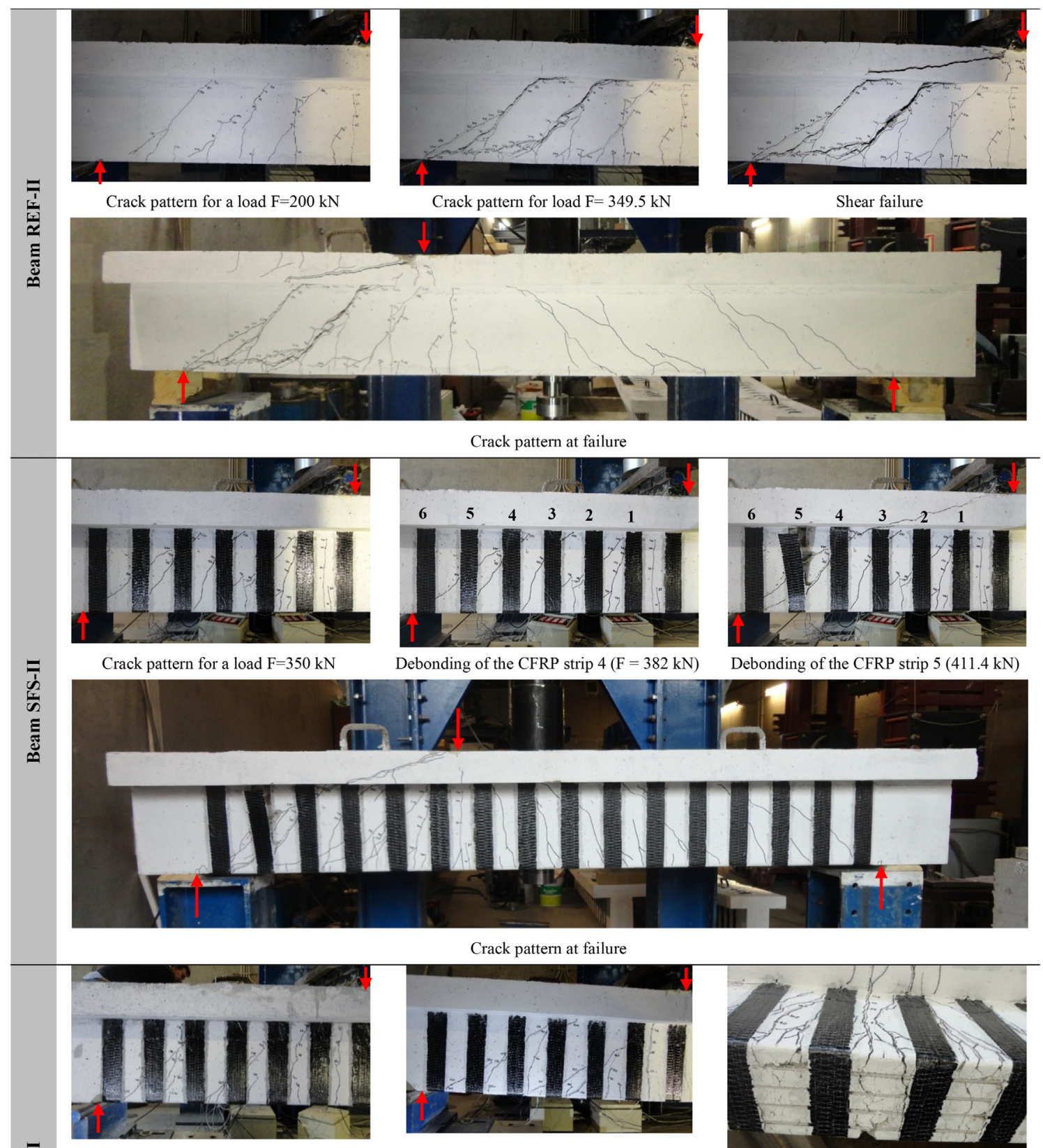

Crack pattern at failure
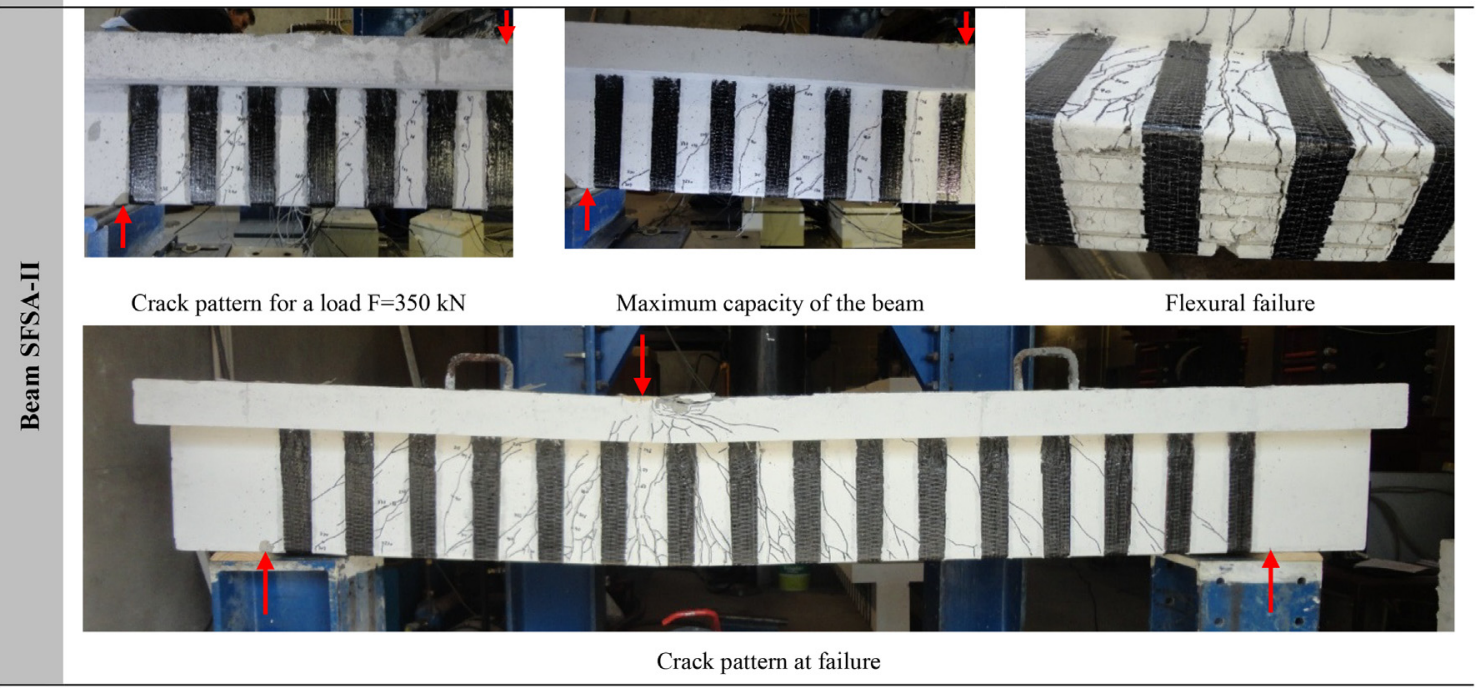

pacity of the beam 


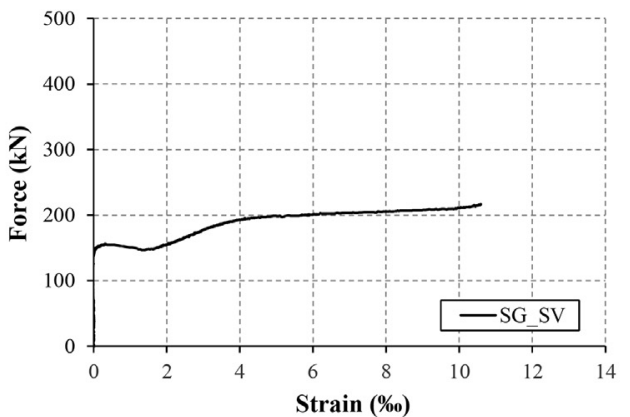

a) Beam REF-I
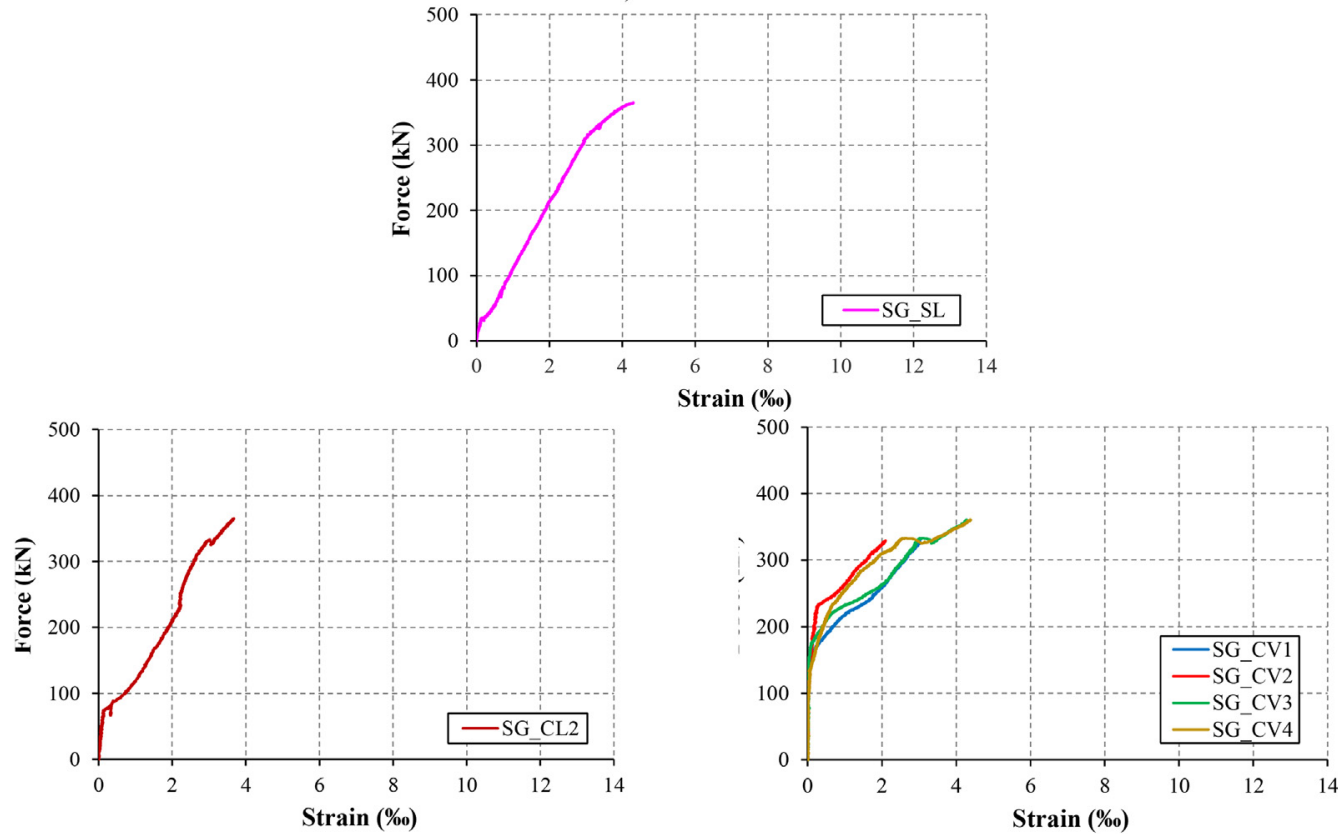

b) Beam SFS-I
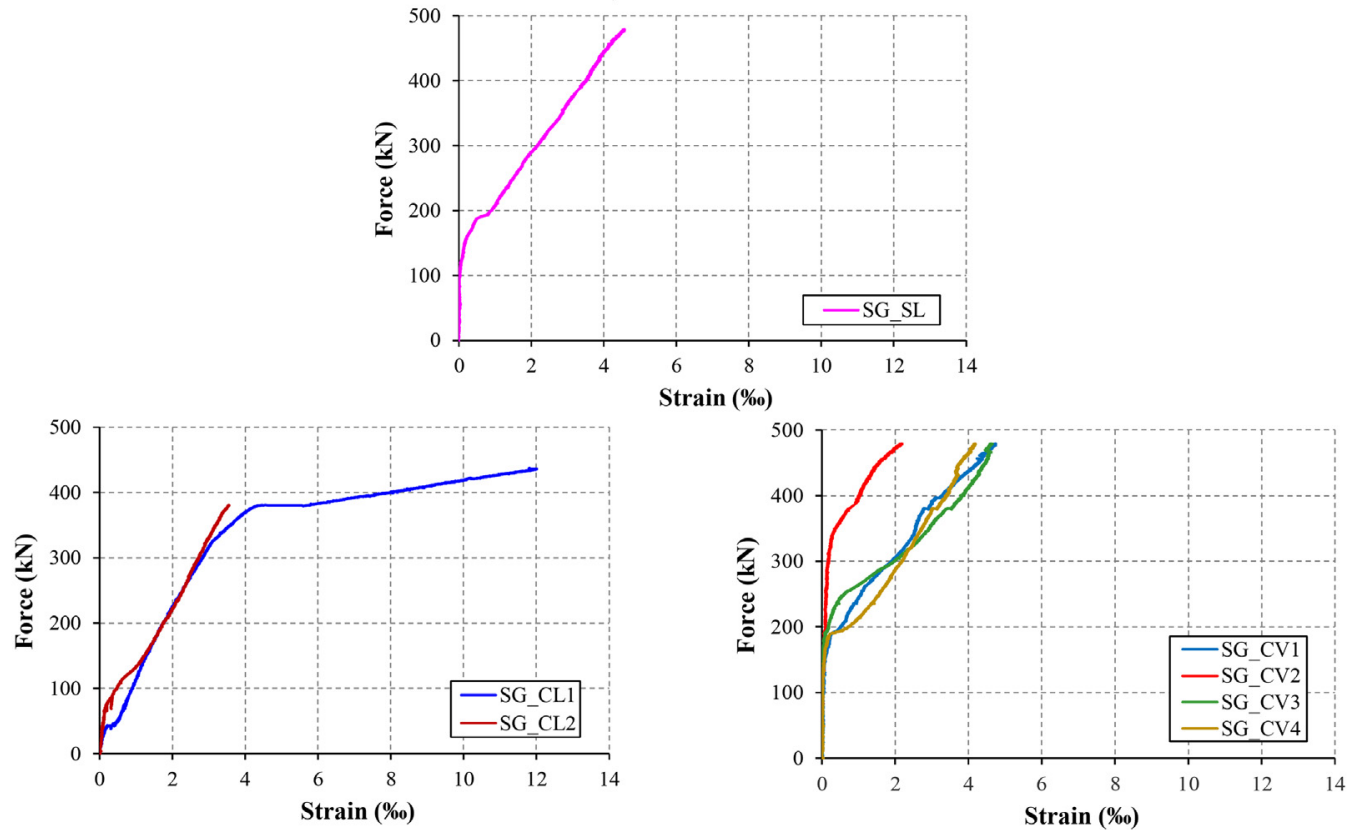

c) Beam SFSA-I

Fig. 9. Variation of strains in the monitored steel reinforcements and CFRP strengthening systems of the tested beams of series I.

strengthening) was recorded in SG_CL1 (positioned in the loaded section), while SG_CL2 has recorded the lowest strain values in all of the tested beams. The maximum strain in SG_CL1 and SG_CL2 of the beam
SFS-II was, respectively, $3.9 \%$ and $2.7 \%$ and the maximum strain in SG_CL1 and SG_CL2 of the beam SFSA-II was, respectively, higher than $15.3 \%$ ( $>15.3 \%$ o due the fact of the failure mode was the rupture of 


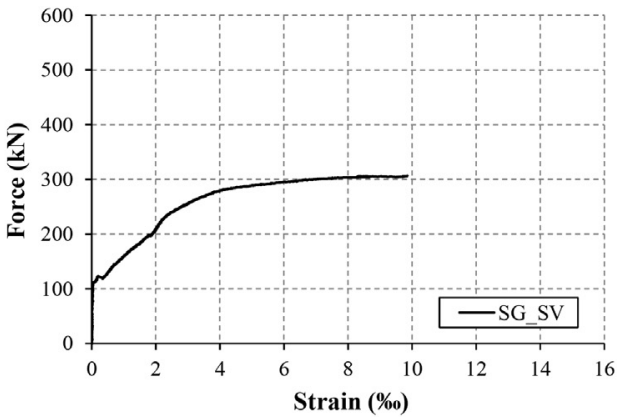

a) Beam REF-II
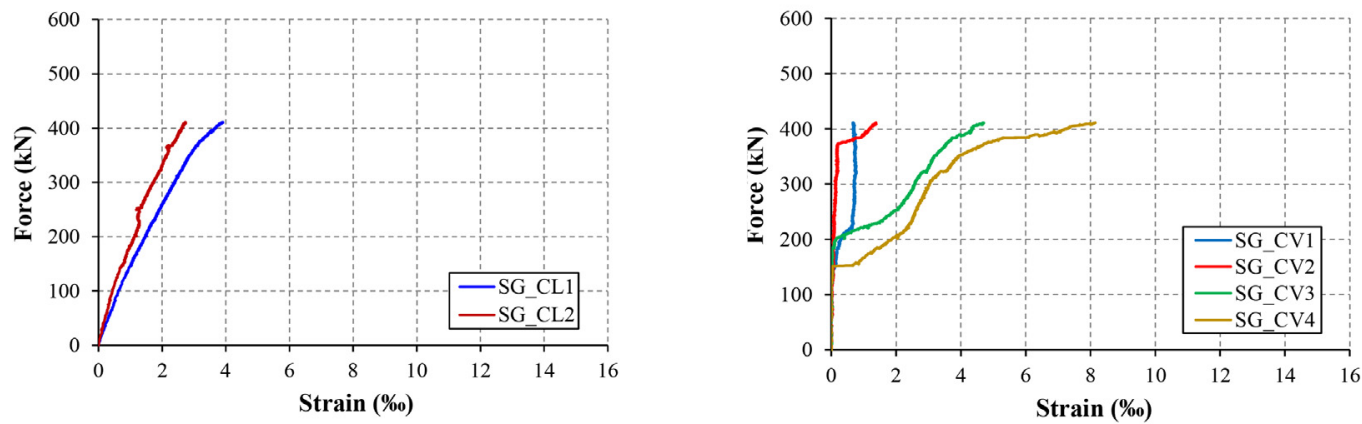

b) Beam SFS-II
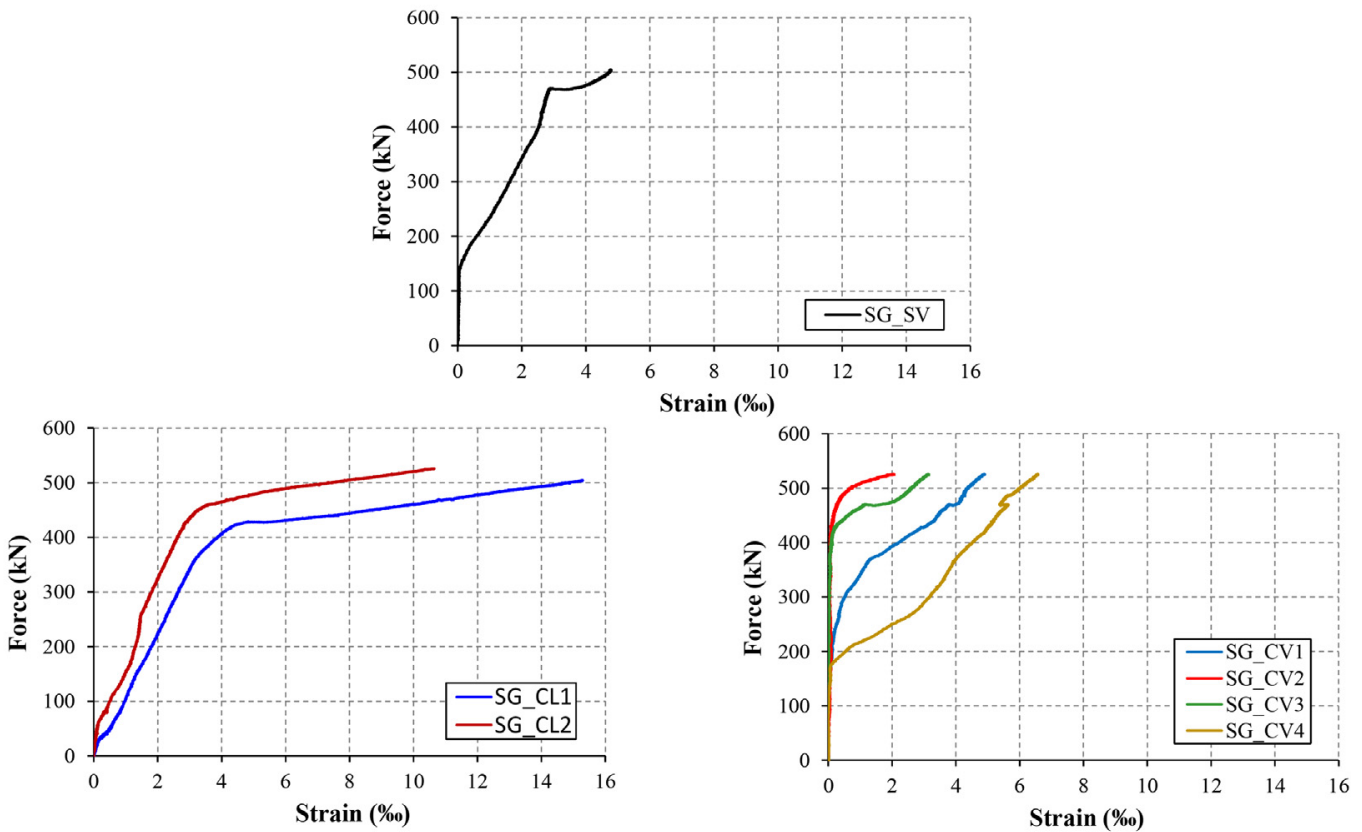

c) Beam SFSA-II

Fig. 10. Variation of strains in the monitored steel reinforcements and CFRP strengthening systems of the tested beams of series II.

the laminate) and $10.5 \%$, which proofs the benefits of the presence of the anchorage of the shear strengthening (high mobilization of the tensile capacity of the CFRP). The strains in the CFRP sheets (shear strengthening) were dependent on the relative distance between the strain gauges and the shear crack crossing the sheets, and it was verified that the value of the strain $\varepsilon_{C F R P}^{\max }$ have varied between $4.4 \%$ and $8.2 \%$.

\subsection{Comparison of the shear strengthening effectiveness}

The shear capacity contributed by the CFRP $\left(V_{f}\right)$ was obtained by subtracting the shear resistance of the reference beam $\left(V_{\text {ref. }}\right)$ from the shear resistance of the strengthened beam $\left(V_{t}\right)$ :
$V_{t}=V_{\text {ref }}+V_{f}$

In this approach it is assumed that the steel stirrups give the same contribution in the strengthened and in the corresponding reference beam. The value of $V_{f}$ for the beams SFS-I and SFS-II was, respectively, $34.3 \mathrm{kN}$ and $38.7 \mathrm{kN}$. As the failure mode of the beams SFSA-I and SFSA-II was by flexural with tensile rupture of the CFRP laminates, it was not possible to obtain the maximum contribution of the CFRP shear strengthening. Thus, for these two beams the real value of $V_{f}$ should be higher than the value obtained using Eq. (1): $105.4 \mathrm{kN}$ for beam SFSA-I and $110.4 \mathrm{kN}$ for beam SFSA-II. However, it is possible to conclude that the contribution $V_{f}$ for the beams SFSA-I and SFSAII (beams with the anchorage system of the shear strengthening) 
Table 4

Strain values in the CFRP laminates (flexural strengthening) and sheets (shear strengthening).

\begin{tabular}{|c|c|c|c|c|c|c|c|}
\hline \multirow[t]{2}{*}{ Monitored CFRP } & \multirow[t]{2}{*}{ Series } & \multirow[t]{2}{*}{ Beam } & \multicolumn{5}{|l|}{ CFRP strains } \\
\hline & & & \multicolumn{2}{|l|}{$\varepsilon^{\mathrm{SG}-\mathrm{CL} 1}(\% o)$} & \multicolumn{2}{|l|}{$\varepsilon^{\mathrm{SG}+\mathrm{CL} 2}(\% o)$} & $\varepsilon_{C F R P}^{\max }(\% o)$ \\
\hline \multirow[t]{4}{*}{ Laminate (flexural strengthening) } & \multirow[t]{2}{*}{ I } & SFS-I & \multirow{2}{*}{\multicolumn{2}{|c|}{$\begin{array}{l}\mathrm{NA}^{(1)} \\
>12.1^{(2)}\end{array}$}} & & $>3.7$ \\
\hline & & SFSA-I & & & $>3.6^{(3)}$ & & $>12.1$ \\
\hline & \multirow[t]{2}{*}{ II } & SFS-II & \multicolumn{2}{|l|}{3.9} & \multicolumn{2}{|l|}{2.7} & 3.9 \\
\hline & & SFSA-II & $>15.3^{(4)}$ & & 10.6 & & $>15.3$ \\
\hline \multirow[t]{7}{*}{ Sheet (shear strengthening) } & \multirow[t]{3}{*}{ Series } & \multirow[t]{3}{*}{ Beam } & \multirow{2}{*}{\multicolumn{2}{|c|}{$\begin{array}{l}\text { Strip Sheet } 4 \text { (Series I) or Strip } \\
\text { Sheet } 3 \text { (Series II) }\end{array}$}} & \multirow{2}{*}{\multicolumn{2}{|c|}{$\begin{array}{l}\text { Strip Sheet } 5 \text { (Series I and Series } \\
\text { II) }\end{array}$}} & $\varepsilon_{C F R P}^{\max }(\% o)$ \\
\hline & & & & & & & \\
\hline & & & $\varepsilon^{S G_{-} C V 1}(\% \circ)$ & $\varepsilon^{\mathrm{SG} \_\mathrm{CV} 2}(\%)$ & $\varepsilon^{\mathrm{SG}-\mathrm{CV} 3}(\%)$ & $\varepsilon^{\mathrm{SG}-\mathrm{CV} 4}(\% o)$ & \\
\hline & \multirow[t]{2}{*}{ I } & SFS-I & $3.0^{(5)}$ & $2.1^{(5)}$ & 4.3 & 4.4 & 4.4 \\
\hline & & SFSA-I & 4.7 & 2.2 & 4.6 & 4.6 & 4.7 \\
\hline & \multirow[t]{2}{*}{ II } & SFS-II & 0.8 & 1.4 & 4.7 & 8.2 & 8.2 \\
\hline & & SFSA-II & 4.9 & 2.1 & 3.1 & 6.6 & 6.6 \\
\hline
\end{tabular}

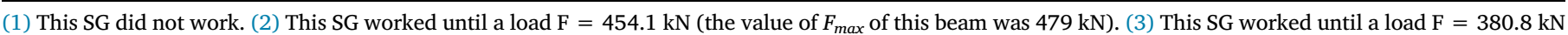

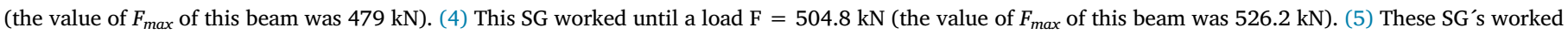
until a load $\mathrm{F}=330 \mathrm{kN}$ for which it was occurred the debonding of the monitored sheet with these two SG's (the value of $F_{\text {max }}$ of this beam was $365.1 \mathrm{kN}$ ).

was, at least, three times the value of $V_{f}$ of the beams SFS-I and SFS-II (beams without the anchorage system of the shear strengthening).

Fig. 11 shows the $V_{f}$ values of the beams SFS-I and SFSA-I and those determined in similar RC beams shear strengthened with NSM CFRP laminates and RC beams shear strengthened with EBR U-shaped CFRP wet lay-up sheets [13] (beams with the same kind of concrete in terms of $f_{c m}$, the same amount of steel stirrups and the same test setup of the beams SFS-I and SFSA-I). According to Fig. 11, the performance of the hybrid CFRP configuration that included the anchorage system for the shear strengthening was significantly higher than the one assured by the other shear strengthening solutions.

\section{Appraisal of the ACI analytical formulation}

\subsection{Flexural strengthening}

The performance of the analytical formulation proposed by ACI [17] for the evaluation of the flexural capacity of RC members flexurally strengthened with FRP was appraised for the case of the tested beams failing in bending. According to this formulation [17], the design resisting bending moment of a representative cross section of a RC beam flexurally strengthened with NSM CFRP laminates, failing in bending, can be estimated from:

$\phi M_{n}=\phi\left(A_{s l} f_{s}\left(d_{s}-\beta_{1} c / 2\right)+\psi_{f} A_{f} f_{f e}\left(d_{f}-\beta_{1} c / 2\right)\right)$

where $\phi$ is a strength reduction factor to attend the ductility level of the cross section [17] and $M_{n}$ is the nominal flexural strength of the cross

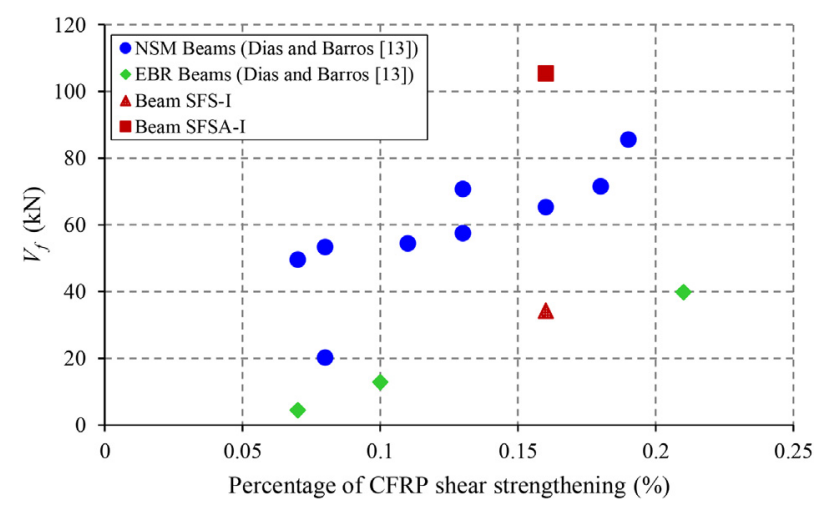

Fig. 11. Comparison of the shear strengthening effectiveness of the tested CFRP configurations of the series I with NSM and EBR CFRP configurations. section. In Eq. (2), $A_{f}$ is the CFRP cross sectional area, $A_{s l}$ and $f_{s}$ are the cross sectional area and the yield stress of the longitudinal tensile steel bars, $c$ is the position of the neutral axis, $f_{f e}$ is the effective tensile stress at ultimate conditions in the $\operatorname{FRP}\left(f_{f e}=E_{f} \varepsilon_{f e}\right.$, where $E_{f}$ is the elasticity modulus of the CFRP and $\varepsilon_{f e}$ is the effective strain level in the CFRP reinforcement at the ultimate limit state) and $\psi_{f}$ is an additional safety factor for the flexural-strengthening contribution of the FRP reinforcement. The parameters $d_{s}$ and $d_{f}$ are the effective depth of the longitudinal steel bars and FRP systems, respectively. The term $\beta_{1}$ is the ratio of the depth of the equivalent rectangular stress block to the depth of the neutral axis [17].

The effective strain $\varepsilon_{f e}$ can be found from:

$\varepsilon_{f e}=\varepsilon_{c u} \times\left(\frac{d_{f}-x}{x}\right)-\varepsilon_{b i} \leqslant \varepsilon_{f d}$

where $\varepsilon_{c u}$ is the maximum usable compressive strain in the concrete $(=0.003), \varepsilon_{b i}$ is the strain level in concrete substrate at the time when FRP is predicted to be installed, and $\varepsilon_{f d}$ is the maximum strain that can be applied to the laminates (debonding strain of the NSM CFRP laminates).

According to ACI [17], for NSM FRP applications, the value of $\varepsilon_{f d}$ may vary from $0.6 \varepsilon_{f u}$ to $0.9 \varepsilon_{f u}$ depending on many factors such as member dimensions, steel and FRP reinforcement ratios, and surface roughness of the FRP. According to the recommendation of ACI [17]: $\varepsilon_{f d}=0.7 \times \varepsilon_{f u}$

The analytical values of the maximum load $\left(F_{\max }^{A n a}\right)$ of the tested NSM flexural strengthened beams, estimated considering the resisting bending moment (obtained using Eq. (2) considering the average values for the material properties and adopting unitary values for all safety factors), are compared to the experimental ones $\left(F_{\max }^{E x p}\right)$ in Table 5. In the case of the beams SFSA-I and SFSA-II, for which the failure mode was the rupture of the CFRP flexural strengthening, it was calculated two values of $F_{\max }^{A n a}$ (one considering Eq. (4) and other considering $\varepsilon_{f d}=\varepsilon_{f u}$.

As beams SFS-I and SFS-II failed in shear, it was not possible to mobilize the maximum potential contribution of the CFRP flexural strengthening. Thus, the real flexural capacity of these beams should be higher than the values registered experimentally. In fact, considering the experimental maximum force obtained in the beams SFS-I and SFS-II (Table 5), the $F_{\max }^{E x p} / F_{\max }^{A n a}$ ratio of these two beams was around 0.8 .

A safe prediction means that the ratio between the experimental and the analytical value of $F_{\max }$ is higher than $1.0\left(F_{\max }^{E x p} / F_{\max }^{A n a} \geqslant 1.0\right)$. From the analysis of the values included in Table 5 , it can be con- 
cluded that ACI formulation provide safe results for the strengthened beams with flexural failure mode (the parameter $F_{\max }^{E x p} / F_{\max }^{A n a}$ was 1.08 and 1.03 for beams SFSA-I and SFSA-II, respectively). In these two beams, for the assumption $\varepsilon_{f d}=\varepsilon_{f u}$, the $F_{\max }^{E x p} / F_{\max }^{A n a}$ ratio was 1.00 and 0.98 for beams SFSA-I and SFSA-II, respectively, which is in accordance to the failure mode obtained in the beams.

\subsection{Shear strengthening}

According to formulation of ACI [17], for the shear strengthening with externally bonded CFRP systems of fiber direction orthogonal to the beam axis, the design contribution of the CFRP to the shear resistance of a concrete member is given by,

$\phi V_{f}=\phi \psi_{f} \frac{A_{f v} f_{f e} d_{f}}{s_{f}}$

where $\phi$ is the strength-reduction factor required by ACI and $V_{f}$ is the nominal shear strength provided by CFRP. In Eq. (5), $\psi_{f}$ is an additional reduction factor, $s_{f}$ is the spacing of the wet lay-up strips of CFRP sheets, $A_{f v}$ is the cross sectional area of CFRP shear reinforcement within spacing $s_{f}$,

$A_{f v}=2 n t_{f} w_{f}$

with $n, t_{f}$ and $w_{f}$ being the number of layers per strip, the thickness of a layer and the width of the strip. The effective stress in the CFRP, $f_{f e}$, is obtained multiplying the elastic modulus of the CFRP, $E_{f}$, by the effective tensile strain (maximum tensile strain that can be achieved in the CFRP system at ultimate load),

$\varepsilon_{f e}=k_{v} \varepsilon_{f u} \leqslant 0.004$ (for $\mathrm{U}-$ wraps) or

$\varepsilon_{f e}=0.004 \leqslant 0.75 \varepsilon_{f u}$ (for fully - wrapped sections)

where $k_{\nu}$ is a bond-reduction coefficient that is dependent of the concrete strength, the type of wrapping scheme used, and the stiffness of the CFRP,

$k_{v}=\frac{k_{1} k_{2} L_{e}}{11900 \varepsilon_{f u}} \leqslant 0.75$

with,

$$
\begin{aligned}
L_{e} & =\frac{23300}{\left(n t_{f} E_{f}\right)^{0.58}} \quad(\mathrm{a}) \\
k_{1} & =\left(\frac{f_{c}^{\prime}}{27}\right)^{2 / 3} \quad(\mathrm{~b}) \\
k_{2}=\frac{d_{f}-L_{e}}{d_{f}} & (\text { for } \mathrm{U}-\text { wraps })
\end{aligned}
$$

In (5) and (9c), $d_{f}$ is the effective depth of CFRP shear reinforcement and $f_{c}^{\prime}$ is the characteristic value of the concrete compressive strength [17]. In (8), $L_{e}$ is the active length and $k_{1}$ and $k_{2}$ are modification factors that account for the concrete strength and for the wrapping scheme, respectively. The length and the force unities of the variables in (8) to (9) are millimeter and Newton, respectively.
In Table 5, the analytical value of the contribution of the CFRP to the shear resistance of the tested beams $\left(V_{f}^{\text {Ana }}\right)$, that were obtained using Eq. (5) considering the average values for the material properties and all safety factors as unitary values, are compared to those registered experimentally $\left(V_{f}^{E x p}\right)$. For the beams SFS-I and SFS-II it was adopted the ACI formulation for the case of U-wraps, while for the beams SFSA-I and SFSA-II it was adopted the ACI formulation for the case of fully-wrapped sections.

The ACI formulation has estimated a CFRP contribution for the shear strengthening that was much larger than the contribution recorded experimentally for the case of SFS-I beam ( $V_{f}^{E x p} / V_{f d}^{A n a}=0.59$ ), which can be justified by a deficient evaluation of the effective strain for the CFRP. The values of $V_{f}^{E x p} / V_{f d}^{A n a}$ were higher than one (safety condition) for the case of SFS-II beam. As already mentioned, the beams SFSA-I and SFSA-II have failing in bending and, consequently, it was not possible to obtain the maximum contribution of the CFRP shear strengthening (the real value of $V_{f}$ should be higher than the value obtained using Eq. (1): 105.4 for beam SFSA-I and 110.4 for beam SFSA-II). However, the limitation of $\varepsilon_{f e}$ to 0.004 (in Eq. (7) for fully-wrapped sections) can justify the lower analytical values of $V_{f}$ for these two beams $(99.1 \mathrm{kN}$ for beam SFSA-I and $49.2 \mathrm{kN}$ for beam SFSA-II), indicating that the condition for determining the effective tensile strain in fully-wrapped shear strengthening configurations provides too conservative shear strengthening contribution.

\section{Conclusions}

The research carried out to evaluate the performance of a hybrid solution using CFRP for the flexural and shear strengthening of RC beams allowed the following conclusions:

- The hybrid solution using CFRP for the strengthening of RC beams that consists on the flexural strengthening with NSM CFRP laminates, on the shear strengthening with discrete strips of EBR Ushape CFRP wet lay-up sheets, complemented with an anchorage system at the extremities of the CFRP shear strengthening proved to be easy and quick to apply.

- Comparison between the behavior of RC beams flexurally strengthened with NSM CFRP laminates and shear strengthened with discrete strips of EBR U-shape CFRP wet lay-up sheets, which were distinguished only by the adoption, or not, of the anchorage system of the shear strengthening, allowed to verify that with this system it was possible to change the brittle shear failure mode observed in the beams without anchorage systems (by premature detachment of the discrete strips of EBR U-shape CFRP wet lay-up sheets) for a ductile flexural failure mode with the yielding of the longitudinal tensile steel reinforcements and rupture of CFRP laminates observed in the beams with anchorage system.

\begin{tabular}{|c|c|c|c|c|c|c|c|c|c|}
\hline \multirow[t]{2}{*}{ Series } & \multirow[t]{2}{*}{ Beam } & \multicolumn{3}{|c|}{ Experimental } & \multicolumn{3}{|c|}{ Proposal of ACI Committee 440 (flexural strengthening) } & \multicolumn{2}{|c|}{$\begin{array}{l}\text { Proposal of ACI Committee } \\
440 \text { (shear strengthening) }\end{array}$} \\
\hline & & $F_{\max }^{\operatorname{Exp}}(\mathrm{kN})$ & $M_{\max }^{E x p(1)}(\mathrm{kN} . \mathrm{m})$ & $V_{f}^{E x p}(\mathrm{kN})$ & $M_{\max }^{\text {Ana (2) }}(\mathrm{kN} . \mathrm{m})$ & $F_{\max }^{A n a}(\mathrm{kN})^{(3)}$ & $F_{\max }^{E x p} / F_{\max }^{A n a}$ & $V_{f}^{A n a}(\mathrm{kN})$ & $V_{f}^{E x p} / V_{f}^{\text {Ana }}$ \\
\hline \multirow[t]{2}{*}{ I } & SFS-I & 365.1 & $>205.4$ & 34.3 & 249.1 & 442.8 & $>0.82$ & 58.5 & 0.59 \\
\hline & SFSA-I & 479.0 & 269.4 & $>105.4$ & $249.1(269.4)$ & $442.8(479.0)$ & $1.08(1.00)$ & 99.1 & $>1.06$ \\
\hline \multirow[t]{2}{*}{ II } & SFS-II & 411.4 & $>231.4$ & 38.7 & 288.4 & 512.7 & $>0.80$ & 35.4 & 1.09 \\
\hline & SFSA-II & 526.2 & 296.0 & $>110.4$ & $288.4(303.4)$ & $512.7(537.0)$ & $1.03(0.98)$ & 49.2 & $>2.24$ \\
\hline
\end{tabular}

Table 5

Experimental versus analytical values.

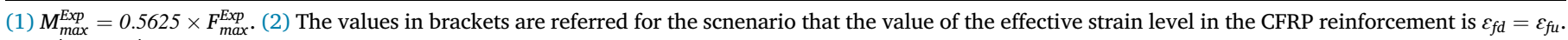

(3) $F_{\max }^{\operatorname{Ana}}=M_{\max }^{A n a} / 0.5625$. 
- A considerable increase of the load carrying capacity was observed in the strengthened RC beams with the hybrid CFRP configuration that included the anchorage system of the shear strengthening. In fact, the beams strengthened with this solution have presented a maximum load 53\% higher the one of the corresponding reference beams (without CFRP), and 31\% higher the one of the strengthened RC beams with the hybrid CFRP configuration but without the anchorage system for the shear strengthening.

- In the strengthened RC beams with the hybrid CFRP configuration that included the anchorage system for the shear strengthening, the deflection at maximum load was more than 2.7 times the deflection at yield initiation, with significant plastic incursion in the steel reinforcement, which assures the required level of deflection ductility for this type of RC structures. Furthemore, this strengthening solution has increased the deflection at maximum load of the strengthened beams in $126 \%$ of the one of the corresponding reference beams (without CFRP) and in $217 \%$ the one of the corresponding strengthened RC beams with the hybrid CFRP configuration but without the anchorage system for the shear strengthening.

- The performance of the hybrid CFRP configuration that included the anchorage system for the shear strengthening was significantly higher than the one assured by other shear strengthening solutions (NSM technique with CFRP laminates and EBR technique with discrete CFRP sheets) that were applied in RC beams similar to those of series I and tested until failure using the same test system adopted in this experimental program.

- Taking into account the results obtained in the tested beams, the performance of the analytical formulation proposed by ACI for the prediction of the flexural and shear strength of a RC member with CFRP laminates was appraised. In the case of flexural strengthening, the ACI formulation provided safe and acceptable estimates. This scenario was not verified for the case of the CFRP shear strengthening, for which the values of the experimental vs. analytical ratio of the parameter $V_{f}$ had a large scatter and an unsafe value was predicted for one of the tested beam.

\section{Declaration of Competing Interest}

The authors declare that they have no known competing financial interests or personal relationships that could have appeared to influence the work reported in this paper.

\section{Acknowledgements}

This work was supported by FEDER funds through the Operational Program for Competitiveness Factors - COMPETE and National Funds through FCT - Portuguese Foundation for Science and Technology under the project Spaflamis POCI-01-0145-FEDER-030956. The authors also acknowledges the support provided by the S\&P® and "Empreiteiros Casais".

\section{References}

[1] Bakis CE, Bank LC, Brown VL, Cosenza E, Davalos JF, Lesko JJ, et al. Fiberreinforced polymer composites for construction - state-of-the-art review. J Compos Constr 2002;6(2):73-87.

[2] Barros JAO, Dias SJE, Lima JLT. Efficacy of CFRP-based techniques for the flexural and shear strengthening of concrete beams. J Cem Concr Compos 2007;29 (3):203-17.

[3] Bilotta A, Ceroni F, Nigro E, Pecce M. Efficiency of CFRP NSM strips and EBR plates for flexural strengthening of RC beams and loading pattern influence. J Compos Struct 2015;124(January):163-75.

[4] Bousselham A, Chaallal O. Shear strengthening reinforced concrete beams with fiber-reinforced polymer: assessment of influencing parameters and required research. ACI Struct J 2004;101(2):219-27.

[5] Mofidi A, Chaallal O. Shear strengthening of RC beams with externally bonded FRP composites: Effect of strip-width-to-strip-spacing ratio. J Compos Constr 2011;15 (5):732-42.

[6] Mostofinejad D, Hosseini SA, Razavi SB. Influence of different bonding and wrapping techniques on performance of beams strengthened in shear using CFRP reinforcement. Constr Build Mater 2016;116:310-20.

[7] El-Hacha R, Riskalla SH. Near-surface-mounted fiber-reinforced polymer reinforcements for flexural strengthening of concrete structures. ACI Struct J 2004;101(5):717-26.

[8] De Lorenzis L, Teng JG. Near-surface mounted FRP reinforcement: An emerging technique for strengthening structures. Compos Part B J 2007;38:119-43.

[9] De Lorenzis L, Nanni A. Shear strengthening of reinforced concrete beams with near-surface mounted fiber-reinforced polymer rods. ACI Struct J 2001;98 (1):60-8.

[10] Dias SJE, Barros JAO. Shear strengthening of RC beams with NSM CFRP laminates: experimental research and analytical formulation. Compos Struct 2013;99:477-90.

[11] Shomali A, Mostofinejad D, Esfahani MR. Effective strain of CFRP in RC beams strengthened in shear with NSM reinforcements. Structures 2020;23:635-45.

[12] Coelho MRF, Sena-Cruz JM, Neves LAC. A review on the bond behavior of FRP NSM systems in concrete. Constr Build Mater J 2015;93:1157-69.

[13] Dias SJE, Barros JAO. Performance of reinforced concrete T beams strengthened in shear with NSM CFRP laminates. Eng Struct 2010;32(2):373-84.

[14] Salib MN. Flexural behavior of RC T- section beams strengthened with different configurations of CFRP laminates. Int J Curr Eng Technol 2012;2(4):418-26.

[15] Bianco V, Barros JAO, Monti G. Three dimensional mechanical model for simulating the NSM FRP strips shear strength contribution to RC beams. Eng Struct J 2009;31(4):815-26.

[16] Rezazadeh M, Barros JAO, Ramezansefat H. End concrete cover separation in RC structures strengthened in flexure with NSM FRP: analytical design approach. Eng Struct J 2016;128:415-27.

[17] ACI 440.2R-17, "Guide for the Design and Construction of Externally Bonded FRP Systems for Strengthening Concrete Structures ", Reported by ACI (American Concrete Institute) Committee 440, Farmington Hills, MI (2017).

[18] Collins MP, Mitchell D. Prestressed concrete structures. Englewood Cliffs, New Jersey: Prentice-Hall Inc; 1997.

[19] EN 206-1, "Concrete - Part 1: Specification, performance, production and conformity", European standard, CEN, 69 pp. (2000).

[20] LNEC E397-1993, "Concrete - Determination of the elasticity modulus under compression", Portuguese specification from LNEC (1993).

[21] EN 10002-1, "Metallic materials - Tensile testing. Part 1: Method of test (at ambient temperature)", European Standard, CEN, Brussels, Belgium, 35 pp. (1990).

[22] ISO 527-5, "Plastics - Determination of tensile properties - Part 5: Test conditions for unidirectional fiber-reinforced plastic composites", International Organization for Standardization (ISO), Geneva, Switzerland, 9 pp. (1997).

[23] Fernandes PM, Silva PM, Sena-Cruz J. Bond and flexural behavior of concrete elements strengthened with NSM CFRP laminate strips under fatigue loading. Eng Struct 2015;84:350-61.

[24] ISO 527-2, "Plastics - Determination of tensile properties - Part 2: Test conditions for moulding and extrusion plastics" International Organization for Standardization (1993). 